\title{
KLF17 empowers TGF- $\beta /$ Smad signaling by targeting Smad3-dependent pathway to suppress tumor growth and metastasis during cancer progression
}

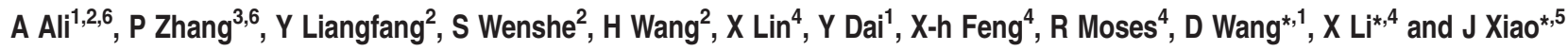

Inhibition of tumor suppressive signaling is linked to cancer progression, metastasis and epithelial-mesenchymal transition (EMT). Transforming growth factor- $\beta 1$ (TGF- $\beta$ )/Smad signaling plays an important role in tumor suppression. Kruppel-like-factor 17 (KLF17) is a negative regulator of metastasis and EMT. However, underlying mechanisms leading to tumor suppressive and antimetastatic function of KLF17 still remains unknown. Here, we show that KLF17 plays an integral role in potentiating TGF- $\beta /$ Smad signaling via Smad3-dependent pathway to suppress tumor progression. Intriguingly, TGF- $\beta /$ Smad3 signaling induces KLF17 expression, generating a positive feedback loop. TGF- $\beta /$ Smad3-KLF17 loop is critical for anti-metastasis and tumor inhibition in cancer cells. Mechanistically, silencing KLF17 reduced Smad3-DNA complex formation on Smad binding element (SBE) and affects the expression of TGF- $\beta /$ Smad target genes. Moreover, KLF17 alters Smad3 binding pattern on chromatin. KLF17 regulates TGF- $\beta$ target genes that are Smad3-dependent. Smad3 and KLF17 physically interact with each other via KLF17 responsive elements/SBE region. Intriguingly, TGF- $\beta$ stimulates the recruitment of KLF17 on chromatin to subsets of metastasis-associated genes. Functionally, depletion of KLF17 enhanced tumorigenic features in cancer cells. KLF17 is critical for full cytostatic function of TGF- $\beta$ /Smad signaling. Clinically, KLF17 expression significantly decreases during advance HCC. KLF17 shows positive correlation with Smad3 levels in cancer samples. Our data shows that enhance KLF17 activity has important therapeutic implications for targeted-therapies aimed at TGF- $\beta /$ Smad3 pathway. These findings define novel mechanism by which TGF- $\beta$ I Smad-KLF17 pathway mutually affect each other during cancer metastasis, provide a new model of regulation of TGF- $\beta /$ Smad signaling by KLF17 and defines new insights into anti-metastatic function of KLF17.

Cell Death and Disease (2015) 6, e1681; doi:10.1038/cddis.2015.48; published online 12 March 2015

Liver cancer represents fifth most common solid tumor among the different cancers. In males, Liver cancer is the second leading cause of cancer death and in females it is the sixth most common cause of cancer death. ${ }^{1}$ Among different liver cancers types, human hepatocellular carcinoma (HCC) is the most critical and represents about $70-85 \%$ of the total liver cancer burden. During HCC high frequency of metastasis, fast tumor progression, recurrence and poor survival rate remain a main challenge for HCC treatment. ${ }^{1,2}$ To date, the exact mechanisms and biology of HCC remains poorly understood which hindered the development of new chemotherapeutic targets. To investigate the mechanisms involved in HCC metastasis and recurrence might be helpful in the development of novel chemotherapeutic targets. ${ }^{2,3}$ Studies have shown that crosstalk and co-operation among different signaling, tumorsuppressor and oncogenic proteins play a crucial role in the epithelial-mesenchymal transition (EMT) and metastasis of cancer. ${ }^{3}$ Among these molecules and signaling Kruppel-likefactor 17 (KLF17) has been shown to have a critical impact on metastasis and cancer progression.

KLFs, which include KLF1-KLF17, are a subfamily of the mammalian Sp/KLF zinc-finger protein family. They have important roles in transcription by binding via their highly conserved DNA-binding domains (DBDs) or C-termini to related $\mathrm{G} / \mathrm{C}$ and CACCC boxes of target genes. ${ }^{4-6} \mathrm{KLFs}$ are implicated in tumor cell proliferation, invasion and metastasis. They function as transcriptional activators or suppressors as determined by regulatory proteins they bind to. ${ }^{7,8} \mathrm{KLF} 17$ gene

\footnotetext{
${ }^{1}$ Nortern Jiangsu People's Hospital (Medical College of Yangzhou University), Yangzhou, Jiangsu 225001, China; ${ }^{2}$ Shanghai Key Laboratory of Regulatory Biology, Key Laboratory of Brain Functional Genomics (Ministry of Education), Shanghai Key Laboratory of Brain Functional Genomics, Institute of Biomedical Sciences, School of Life Sciences, East China Normal University, 500 Dongchuan Road, Shanghai 200241, China; ${ }^{3}$ Department of Pathology, the Second Chengdu Municipal Hospital, Chengdu, Sichuan 610017, China; ${ }^{4}$ Department of Molecular and Cellular Biology, Baylor College of Medicine, One Baylor Plaza, Houston, TX 77030, USA and ${ }^{5}$ Department of Orthopedic Oncology, Changzheng Hospital, The Second Military Medical University, 415 Fengyang Road, Shanghai 200003, China

${ }^{*}$ Corresponding author: D Wang, Nortern Jiangsu People's Hospital (Medical College of Yangzhou University), Yangzhou, Jiangsu, 225001, China. Tel: +86 0514 87373039; E-mail: daxinw2002@sina.com

or J Xiao, Department of Orthopedic Oncology, Changzheng Hospital, The Second Military Medical University, 415 Fengyang Road, Shanghai, 200003 , China. Tel: +86 02154345018; E-mail:jianruxiao@ 163.com

or X Li, Department of Molecular and Cellular Biology, Baylor College of Medicine, One Baylor Plaza, Houston, TX 77030, USA. Tel: +713 7983817; E-mail: xiaotaol@ bcm.edu ${ }^{6}$ These authors contributed equally to this work.

Abbreviations: ChIP, chromatin immnuoprecipitation; EMSA, electrophoretic mobility shift assay; EMT, epithelial-mesenchymal-transition; HCC, human hepatocellular carcinoma; KLF-17, Kruppel-like-factor-17; KLF17RE, KLF17 responsive elements; MTT, 3-(4,5-dimethylthiazol-2-yl)-2,5-diphenyltetrazolium bromide; PARP, poly (ADPribose) polymerase; PBS, phosphate-buffered saline; RNAi, RNA interference; SATB1, sequence-binding protein-1; SBE, Smad binding element; SBE-Luc, SBE-containing luciferase reporter; siRNA, small interference RNA; TGF- $\beta 1$, transforming growth factor- $\beta 1$

Received 28.10.14; revised 01.1.15; accepted 19.1.15; Edited by G Ciliberto
} 
encodes a suppressor of cancer cell metastasis. ${ }^{9-12}$ KLF17 suppresses EMT and metastasis by directly binding to $t$ he promoter and inhibiting the transcription of Id1, which is a key regulator of tumorigenesis, EMT, angiogenesis, invasion and metastasis. ${ }^{12,13}$ Forced expression of KLF17 in highly metastatic breast cancer cells inhibits the ability of these cells to metastasize to the lung. ${ }^{11,12}$ Conversely, depletion of KLF17 enhances cancer cell migration and invasion. ${ }^{9-11}$ In addition, reduced expression of KLF17 is a predictor of metastasis in breast cancer, lung adenocarcinoma and HCC. ${ }^{9,12,13}$ Patients with decreased level of KLF17 have poor prognosis as exhibiting greater tumor size and advanced stages. ${ }^{10,11}$

Transforming growth factor- $\beta 1$ (TGF- $\beta 1$ ) have a unique and pivotal role in homeostasis, wound healing, fibrosis, angiogenesis, carcinogenesis and differentiation of the cell. ${ }^{14-16}$ It is a potent inhibitor of epithelial cell proliferation, and induces apoptosis. ${ }^{17-19}$ TGF- $\beta 1$ interacts with TGF- $\beta$ RII, which in turn activates TGF- $\beta$ RI. Smad2 and Smad3 are phosphorylated at the $\mathrm{C}$ terminus by activated TGF- $\beta \mathrm{RI}$ receptor and form heteromeric complexes with Smad4 ${ }^{20-22}$ Ultimately, the Smad2/3/4 complex translocates into the nucleus and binds to specific regulatory elements on target genes. ${ }^{23,24}$ The role of TGF- $\beta$ signaling as a tumor suppressor is best illustrated by the presence of inactivating mutations in genes encoding TGF- $\beta$ receptors and Smads in human carcinomas, and by studies of tumor development in mouse models. ${ }^{25,26}$ Mutations in TGFBRII are frequently found in colon cancers, gastric cancers and gliomas with microsatellite instability. ${ }^{27,28}$ Mutations of the Smad2/3/4 encoding gene sequences have been detected in several carcinomas. ${ }^{29}$ TGF- $\beta$ dependent transcription can have cross-talks with other signaling pathways through physical interactions and functional co-operativity between Smads and other transcription factors. $^{30-32}$

Here, in this study we address the issue that how KLF17 control cancer progression and metastasis in cancer cells. We found that KLF17 potentiates TGF- $\beta /$ Smad-dependent signaling to inhibit tumor formation. In search for the molecular mechanisms, we identified that KLF17 has an integral role in potentiating TGF- $\beta / S$ mad3-dependent signaling during tumorigenesis. Intriguingly, TGF- $\beta / \mathrm{Smad} 3$ signaling and KLF17 forms a novel positive-feedback loop. KLF17 is important for the full transcriptional activity of TGF- $\beta / \mathrm{Smad} 3$ signaling. Knockdown of KLF17 decreased the binding of activated Smad3 to TGF- $\beta /$ Smad target gene promoters. Importantly, this novel crosstalk between KLF17 and Smad3 occurs on a subset of metastasis-associated genes. KLF17 and Smad3 physically interact with each other via KLF17 responsive elements (KLF17RE)/smad binding elements (SBE) region. Thus, TGF- $\beta /$ Smad3-KLF17 loop is critical for anti-metastasis and tumor inhibition in cancer cells.

\section{Results}

TGF- $\boldsymbol{\beta}$ enhances KLF17 expression via Smad3. Using bioinformatics analysis, NCBI database, we found SBEs within KLF17 promoter. This finding prompted us to analyze the potential regulation of KLF17 by TGF- $\beta$. In a dosedependent manner, TGF- $\beta$ was able to induce the transcriptional activity of KLF17-luc reporter (Figure 1a and Supplementary Figure 1A). Ectopic expression of Smad3/4 also induced KLF17-luc activity (Figure 1b). TGF- $\beta$ treatment also enhanced KLF17 protein levels in multiple cancer cell lines (Figure 1c). While, depletion of Smad3 reduced KLF17 expression in different cancer cells (Supplementary Figure 1B).

There are two potential SBE sites in KLF17 promoter. To determine the functional importance of these SBEs in mediating TGF- $\beta$-regulated KLF17 expression, we designed oligo probes containing each putative SBE and tested their ability to bind to purified Smad3 protein. We found that only SBE-2 bound strongly to Smad3 (Supplementary Figure 1C). Moreover, mutation of SBE-2 within the KLF17-luc reporter blunted its response to TGF- $\beta$ induction, indicating that an activated Smad complex binds to SBE-2 to induce KLF17 transcription (Figure 1d). As expected, we observed a TGF- $\beta$ induced Smad complex binding to SBE-2 in an electrophoretic mobility shift assay (EMSA) using nuclear extract (Figure 1e). Furthermore, we detected the enrichment of Smad3 and $\mathrm{AcH} 4$ (acetylated histone 4 ) in TGF- $\beta$ responsive (SBE-2) region on KLF17 promoter by chromatin immnuoprecipitation (ChIP) assay (Figures $1 \mathrm{f}$ and $\mathrm{g}$ ). These results explain some of the published results that TGF- $\beta$ can induce the expression of KLF17 target genes. ${ }^{33}$

KLF17 regulates TGF- $\beta$ target genes by modulating Smad3-DNA complex formation. Previous publications indicate that some of the genes directly regulated by TGF- $\beta$ can also be targets of KLF17. ${ }^{34,35}$ To investigate the role of KLF17 in TGF- $\beta /$ Smad-mediated signaling, we manipulated expression of KLF17 by RNA interference (RNAi) in cancer cell lines and tested TGF- $\beta$ responsive SBEcontaining luciferase reporter (SBE-Luc) activities. We found that SBE-Luc transcriptional activity was higher in control cells than in KLF17 knockdown cells following TGF- $\beta$ treatment (Figure $2 \mathrm{a}$ and Supplementary Figure $2 \mathrm{~A}$ ). In contrast overexpression of KLF17 further enhanced SBE-Luc transcriptional activity in TGF- $\beta$-treated cells (Figure $2 b$ ). On sufficient depletion of KLF17 by RNAi (Figure 2a, right panel and Supplementary Figure 2B), expression of p21, ATF-3, $B C L-2$, ID1 and C-Myc genes that are regulated by TGF- $\beta$ / Smad signaling showed attenuated response to TGF- $\beta$ treatment (Figures $2 \mathrm{c}-\mathrm{g}$ and Supplementary Figures $2 \mathrm{C}$ and D).

To investigate the molecular mechanism underlying KLF17 regulated expression of TGF- $\beta$ target genes, we performed ChIP analysis of the p21 promoter, a well-known target of TGF- $\beta /$ Smad3 signaling. We observed a decreased recruitment of Smad3 to p21 promoter in KLF17 knockdown cells (Figure 2h). Furthermore, quantitative-ChIP analysis of p21 promoter in response to TGF- $\beta$ with indicated time period obtained similar results (Figure 2i). These data indicate that KLF17 regulates TGF- $\beta$ target genes most likely through regulating Smad3.

KLF17 induces Smad3 to generate a positive feedback loop. Next, we sought to address how KLF17 affects the Smad3-dependent signaling. We found that overexpression of KLF17 in HepG2 cells increased Smad3, but not Smad4 
a

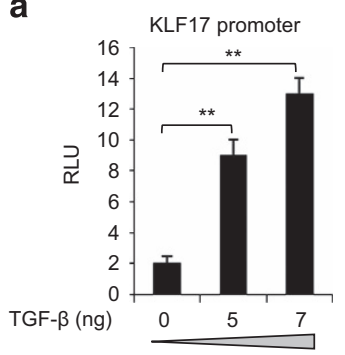

d

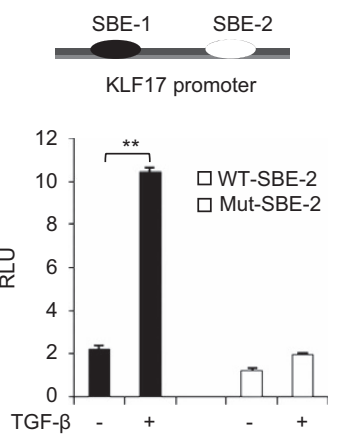

b

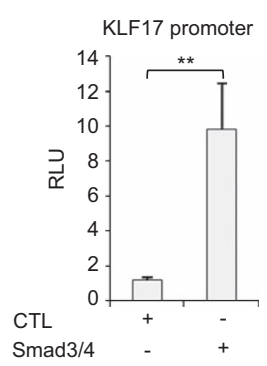

C

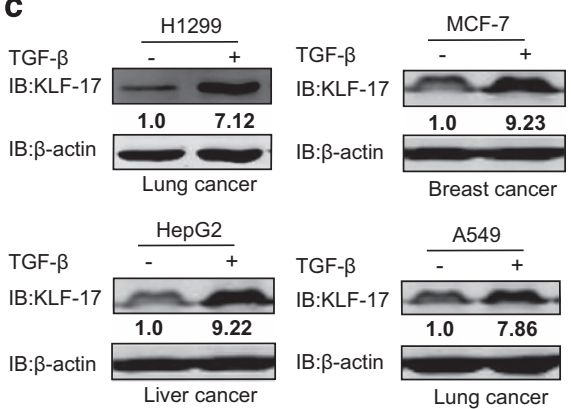

e

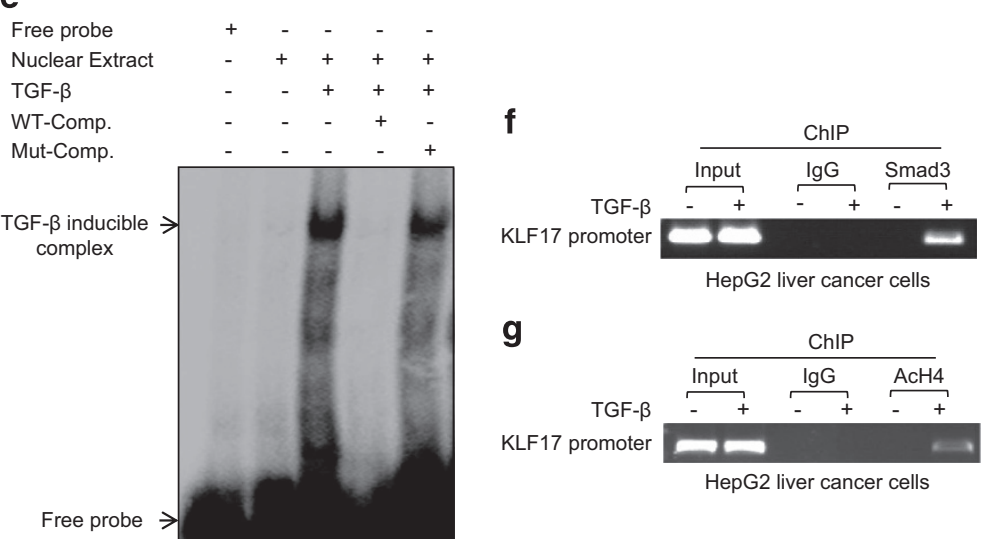

Figure 1 Upregulation of KLF17 expression by TGF- $\beta$-SMAD3 signaling (a) HepG2 cells were transfected with a KLF17 reporter construct $(2 \mu \mathrm{g})$, treated with different doses of TGF- $\beta$ for $24 \mathrm{~h}$ prior to lysis, and analyzed for luciferase activity. Data are representative of three independent experiments (mean \pm S.D.). (Two-tailed Student's $t$-test, ${ }^{*} P<0.05$, $\left.{ }^{* *} P<0.005\right)$. (b) HepG2 cells were co-transfected with a KLF17 reporter construct $(2 \mu \mathrm{g})$ in combination with Smad3/4 (100 ng) expression plasmids for $24 \mathrm{~h}$, and then analyzed for luciferase activity. The average was calculated based on three independent experiments with mean \pm S.D. (Two-tailed Student's $t$-test, ${ }^{*} P<0.05,{ }^{* \star} P<0.005$ ). (c) A549, HepG2, MCF-7 and H1299 cells were treated with $5 \mathrm{ng} / \mathrm{ml} \mathrm{TGF-} \beta$ and analyzed by Western blot. (d) Schematic representation of putative SBE boxes in the KLF17 promoter. The white arrow indicates functional SBE in KLF17 promoter. HepG2 cells were transfected with wild-type $(2 \mu \mathrm{g})$ or mutated $(2 \mu \mathrm{g}) \mathrm{SBE}$ KLF17 luciferase reporter constructs. Cells were then left untreated or treated with $5 \mathrm{ng} / \mathrm{ml} \mathrm{TGF-} \beta$ for $24 \mathrm{~h}$, and luciferase activity was measured. Data are representative of three independent experiments with mean \pm S.D. (Two-tailed Student's t-test, ${ }^{* *} P<0.05$ ). (e) EMSA was performed using nuclear extract from HepG2 cells treated with $5 \mathrm{ng} / \mathrm{ml}$ TGF- $\beta$ for $24 \mathrm{~h}$. About $2 \mu \mathrm{g}$ of nuclear extract protein were incubated with ${ }^{32} \mathrm{p}$-radiolabeled probe containing SBE box from KLF17 promoter. (f) HepG2 cells were treated with $5 \mathrm{ng} / \mathrm{ml}$ TGF- $\beta$ for $24 \mathrm{~h}$, and chromatin immunoprecipitation were performed with indicated antibodies. (g) HepG2 cells were treated with $5 \mathrm{ng} / \mathrm{ml} \mathrm{TGF}-\beta$ for $24 \mathrm{~h}$, and chromatin immunoprecipitation were performed with indicated antibodies

mRNA level (Figure 3a). On the contrary, silencing KLF17 in HepG2 cells reduced Smad3, but not Smad4 mRNA levels (Figure 3b). By Western blot, we verified our finding that KLF17 positively regulates Smad3 (Figures $3 c$ and d). Knockdown of KLF17 expression in multiple cancer cell lines showed similar decrease in Smad3 mRNA levels (Figure 3e), substantiating that KLF17 induces Smad3 expression in multiple cells.

Given that KLF17 functions as a transcription factor to regulate its target gene expression at transcriptional level, ${ }^{9-11}$ we intend to determine if Smad3 is a direct target gene of KLF17. By co-expressing a Smad3 luciferase reporter (Smad3-Luc) along with KLF17, we found that KLF17 was able to induce Smad3-Luc activity (Figure 3f). KLF17 has been known to bind to CACCC box sequences. ${ }^{6-8}$ We found three KLF17 responsive elements in the Smad3 promoter region (Figure $3 \mathrm{~g}$ ). We designed oligo probes corresponding to these sites, and detected the binding of KLF17 to KLF17RE-2, but not to the others sites by EMSA (Supplementary Figure $3 A$ ). Furthermore, we mutated the KLF17RE-2 in the Smad3-Luc reporter and found that KLF17 was unable to induce Smad3 activity, suggesting that the KLF17RE-2 site is critical for regulation of Smad3 by KLF17 (Figure 3g). Consistently, in vivo recruitment of KLF17 to the Smad3 promoter by ChIP analysis (Figure $3 \mathrm{~h}$ ) and in vitro binding of KLF17 to KLF17RE-2 elements by EMSA analysis (Figure 3i) all demonstrated that KLF17 directly regulates transcription of Smad3.

KLF17 regulates a panel of TGF- $\beta / S m a d 3-d e p e n d e n t$ target genes. Based on the above findings, we hypothesize that KLF17 may have broader impact on the transcriptional regulation of TGF- $\beta /$ Smad-dependent target genes. We thus examined the levels of several TGF- $\beta / S m a d-d e p e n d e n t$ target genes in KLF17 knockdown cells and control cells. Using Real time-PCR (RT-PCR) approach, we observed changes in the expression of several TGF- $\beta /$ Smad-dependent target genes between control and KLF17 knockdown cells (Figure 4a), suggesting that KLF17 indeed influences the transcriptional program of the TGF- $\beta /$ Smad pathway. Importantly, genes upregulated by $S$ mad3/4 in response to TGF- $\beta$, including p15, PUMA, ATF-3, TGLN, CBFA-1 and 14-3$3 \delta^{36-38}$ were repressed in the absence of KLF17 (Figure 4a). In contrast, genes repressed by Smad3/4, such as 

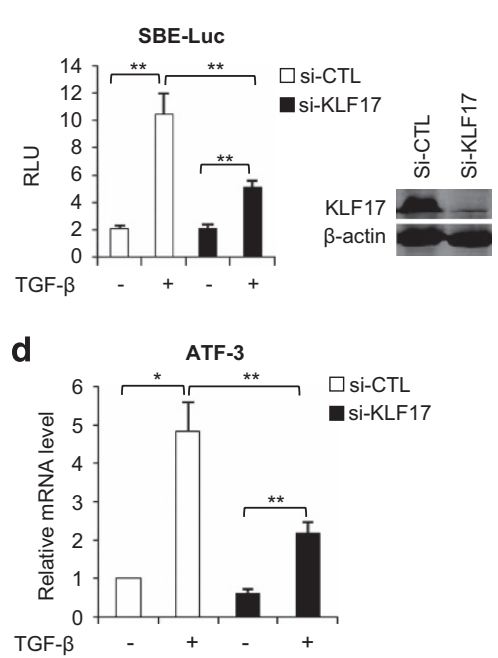

9

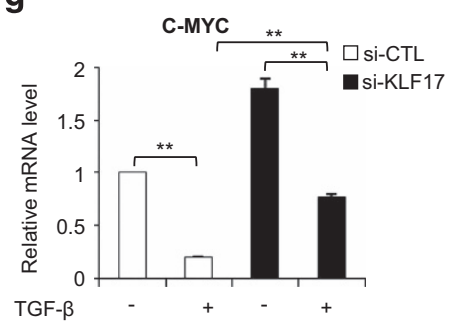

b

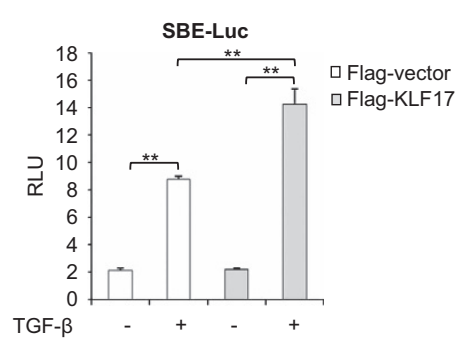

e

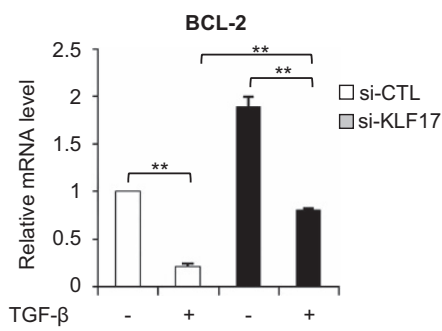

h

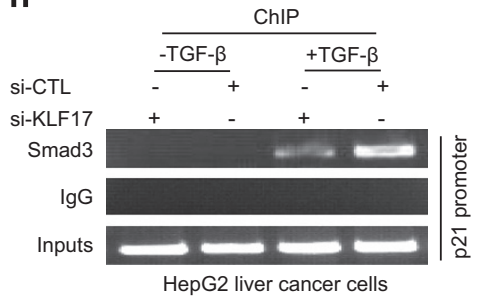

C

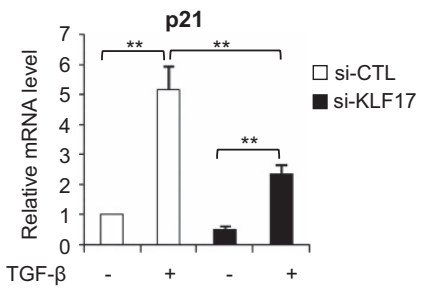

f

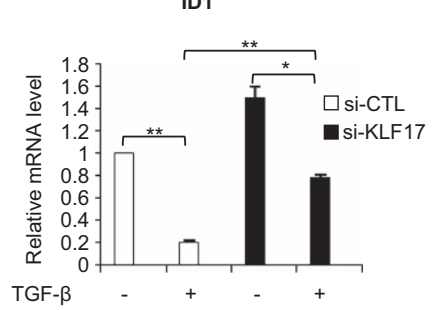

i

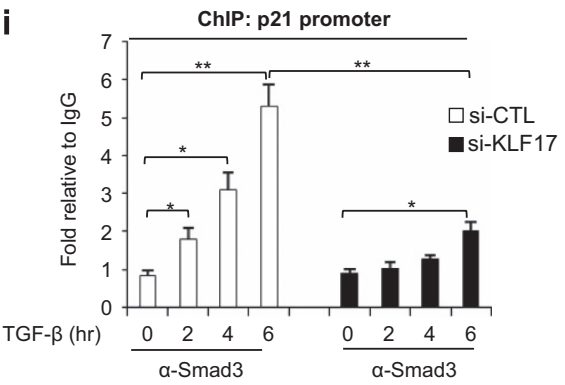

Figure 2 KLF17 is required for full transcriptional activity of TGF- $\beta$-SMAD pathway (a) HepG2 cells were transfected with control siRNA or siRNA targeting against KLF17 $(20 \mathrm{nM})$ for $48 \mathrm{~h}$ and then transfected with SBE reporter construct $(2 \mu \mathrm{g})$, and left untreated or treated with $5 \mathrm{ng} / \mathrm{ml} \mathrm{TGF}-\beta$ for $24 \mathrm{~h}$ prior to lysis, and analyzed for luciferase activity. Data are representative of three independent experiments (mean \pm S.D.). (Two-tailed Student's $t$-test, $\left.{ }^{*} P<0.05,{ }^{* \star} P<0.005\right)$. (b) HepG2 cells were co-transfected with vector encoding KLF17 and SBE luciferase reporter for $24 \mathrm{~h}$ prior to lysis, and analyzed for luciferase activity. Data are representative of three independent experiments (mean \pm S.D.). (Two-tailed Student's $t$-test, ${ }^{*} P<0.05,{ }^{* *} P<0.005$ ). (c-g) HepG2 cells were transfected with control siRNA or siRNA targeting against KLF17 (20 nM) for $48 \mathrm{~h}$, and then left untreated or treated with $5 \mathrm{ng} / \mathrm{ml} \mathrm{TGF}-\beta$ for $14 \mathrm{~h}$, and analyzed by RT-PCR analysis. Data are representative of three independent experiments (mean \pm S.D.). (Two-tailed Student's t-test, ${ }^{\star} P<0.05,{ }^{* \star} P<0.005$ ). (h) HepG2 cells were transfected with control siRNA or siRNA targeting against KLF17 (20 nM) for $48 \mathrm{~h}$, and then left untreated or treated with $5 \mathrm{ng} / \mathrm{ml} \mathrm{TGF}-\beta$ for indicated time points and analyzed by ChIP assay with indicated antibodies. (i) HepG2 cells were transfected with control siRNA or siRNA targeting against KLF17 $(20 \mathrm{nM})$ for $48 \mathrm{~h}$, and then left untreated or treated with $5 \mathrm{ng} / \mathrm{ml} \mathrm{TGF-} \beta$ with indicated time points and analyzed by ChIP assay with Smad3 antibody. Data are representative of three independent experiments (mean \pm S.D.). (Two-tailed Student's $t$-test, ${ }^{\star} P<0.05,{ }^{* *} P<0.005$ )

CEACAM-5, MMP-1, C-MYC, BCL-2, ID1 and $h T E R T^{36,39,40}$ were de-repressed when KLF17 was depleted, indicating a positive regulation of Smad3 by KLF17 (Figure 4a).

Next, we sought to address the impact of KLF17 on regulation of TGF- $\beta$ Smad-independent target genes. We selected a list of genes, which are regulated by TGF- $\beta$ signaling in Smad-independent manner such as ERG-1, PTEN, NovH, CTGF, RhoA, S100A2, COL1A2 and IGFBP-5. Intriguingly, we observed no significant changes in the expression of these genes on depletion of KLF17 (Figure 4b). In conclusion, these data suggest that KLF17 has the ability to regulate TGF- $\beta /$ Smad-dependent target genes, but not those independent of Smads.

Joint regulation of metastasis-associated genes by KLF17-Smad3 signaling. Previous studies have shown transcriptional cross-talks between TGF- $\beta /$ Smad signaling and other pathways. These cross-talks require adjacent binding sites for Smad and other transcription factors. ${ }^{30-32}$ Intriguingly, we found adjacent binding sites (within $50 \mathrm{bp}$ ) for
KLF17 and SBE on a subset of metastasis-associated genes including MTDH, sequence-binding protein-1(SATB1), SPARC, KAl1 and CADM1 (Figure 5a). These sites were termed KLF17RE/SBE regions. Co-silencing of KLF17 and Smad3 resulted in significant upregulation of $\mathrm{MTDH}$, SATB1 and SPARC genes and downregulation of KAl1 and CADM1 genes in comparison with independent depletion of either KLF17 or Smad3 (Figures 5b-f), suggesting that cross-talks between KLF17 and Smad3 occurs on these genes. Next, HepG2 cells were transfected with a control vector or a KLF17 expression plasmid in the presence or absence of TGF- $\beta$. RT-PCR analysis was performed and showed that the combined effect (KLF17+TGF- $\beta$ ) was much stronger than that of KLF17 transfection or TGF- $\beta$ treatment alone (Figures $5 \mathrm{~g}-\mathrm{i}$ ).

Next, we silenced Smad3 expression in HepG2 cells followed by ChIP analysis. The results showed decreased recruitment of both Smad3 and KLF17 to special AT-rich SATB1 promoter in TGF- $\beta$-treated cells depleted Smad3 (Figure 5j and Supplementary Figure 4A), consistent with that 
a

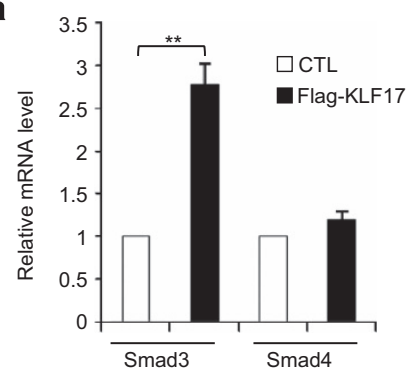

d

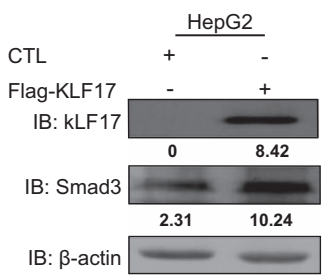

g

KLF17 Binding Sequence CACCC
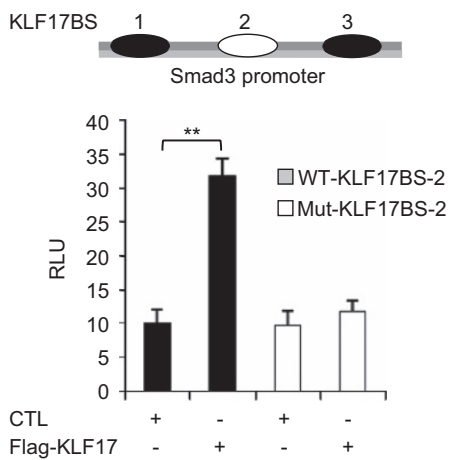

b

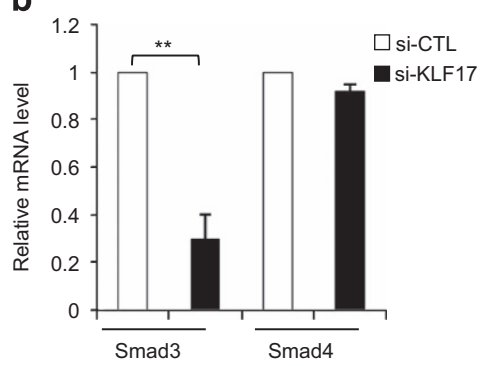

e

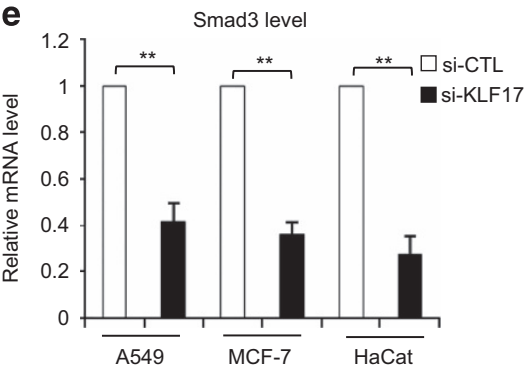

h

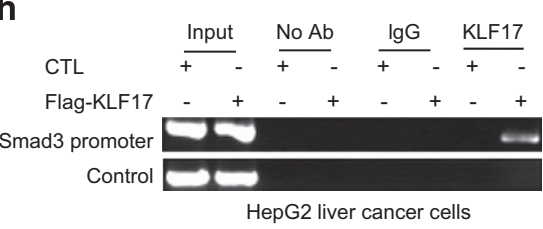

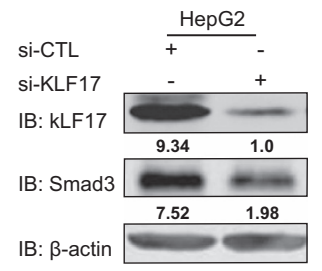

f
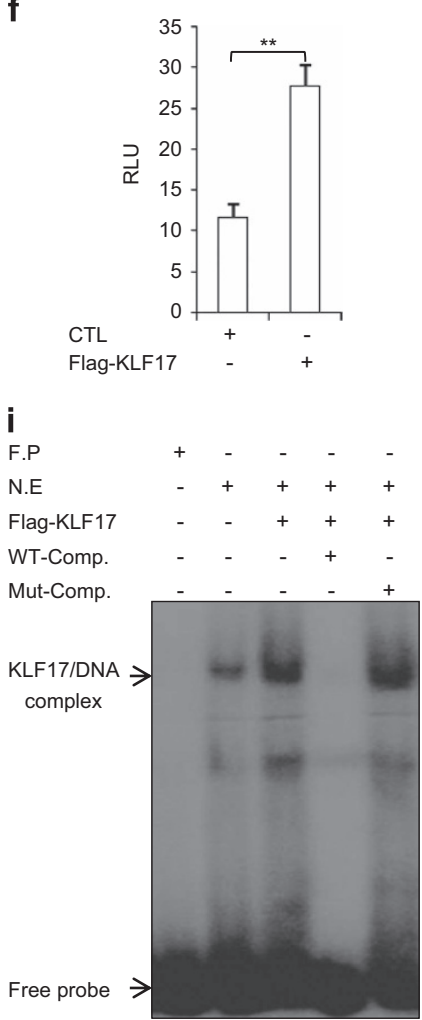

Figure 3 KLF17 promotes SMAD3 transcription (a) HepG2 cells were transfected with either flag vector or expression plasmid encoding KLF17 for $24 \mathrm{~h}$ and subjected to RTPCR analysis. Data are representative of three independent experiments (mean \pm S.D.). (Two-tailed Student's $t$-test, ${ }^{*} P<0.05,{ }^{* *} P<0.005$ ). (b) HepG2 cells were transfected with control siRNA or siRNA targeting against KLF17 $(20 \mathrm{nM})$ for $48 \mathrm{~h}$, and analyzed by RT-PCR. Data are representative of three independent experiments (mean \pm S.D.). (Twotailed Student's $t$-test, $\left.{ }^{*} P<0.05,{ }^{* *} P<0.005\right)$. (c) HepG2 cells were transfected with control siRNA or siRNA targeting against KLF17 (20 nM) for $72 \mathrm{~h}$, and analyzed by immunoblot with indicated antibodies. (d) HepG2 cells were transfected with either flag vector or expression plasmid encoding KLF17 for $24 \mathrm{~h}$ and subjected to immunoblot analysis with indicated antibodies. (e) Cancer cells were transfected with control siRNA or siRNA targeting against KLF17 (20 nM) for $48 \mathrm{~h}$, and analyzed by RT-PCR. The average was calculated based on three independent experiments with mean \pm S.D. (Two-tailed Student's $t$-test, ${ }^{\star} P<0.05,{ }^{\star *} P<0.005$ ). (f) HepG2 cells were co-transfected with Smad3 reporter construct and expression plasmid encoding KLF17 for $24 \mathrm{~h}$ prior to lysis, and analyzed by luciferase assay. Data are representative of three independent experiments (mean \pm S.D.). (Two-tailed Student's $t$-test, ${ }^{*} P<0.05,{ }^{* \star} P<0.005$ ). (g) Schematic representation of putative KLF17BS boxes in Smad3 promoter. The white arrow indicates functional KLF17BS in Smad3 promoter. HepG2 cells were transfected with wild-type $(2 \mu \mathrm{g})$ or mutated $(2 \mu \mathrm{g}) \mathrm{KLF} 17 \mathrm{BS}$ along with Smad3 luciferase reporter constructs for $24 \mathrm{~h}$ and then analyzed by luciferase assay. Data are representative of three independent experiments (mean \pm S.D.). (Two-tailed Student's $t$-test, ${ }^{*} P<0.05$, ${ }^{* \star} P<0.005$ ). (h) HepG2 cells were transfected with either flag vector or expression plasmid encoding KLF17 for $24 \mathrm{~h}$ and subjected to ChIP analysis with indicated antibodies. (i) HepG2 cells were transfected with either flag vector or expression plasmid encoding KLF17 for $24 \mathrm{~h}$ and subjected to EMSA analysis with radiolabel $\mathrm{p}^{32}$ probe corresponding to KLF17BS in Smad3 promoter

activated Smad3 cooperates with KLF17 via promoter region in response to TGF- $\beta$.

To further validate the co-operation between the Smad3 and KLF17 proteins in the KLF17RE/SBE regulatory region, we performed EMSA. Incubation of nuclear extract with a probe corresponding to the KLF17RE/SBE region resulted in formation of a putative KLF17-Smad-DNA complex (Supplementary Fig. 4B, Lane2), which was further enhanced in the presence of TGF- $\beta$ (Supplementary Fig. 4B, Lane3). Addition of Smad3, Smad4 or KLF17 antibody alone significantly attenuated the formation of this complex (Supplementary Fig. 4B Lane4, 5 and 6), suggesting that TGF- $\beta$ stimulates the formation of KLF17-Smad-DNA complex in this region. Finally, addition of both KLF17 and Smad3 antibodies nearly abolished the formation of this complex (Supplementary Fig. 4B, Lane7), substantiating that these 

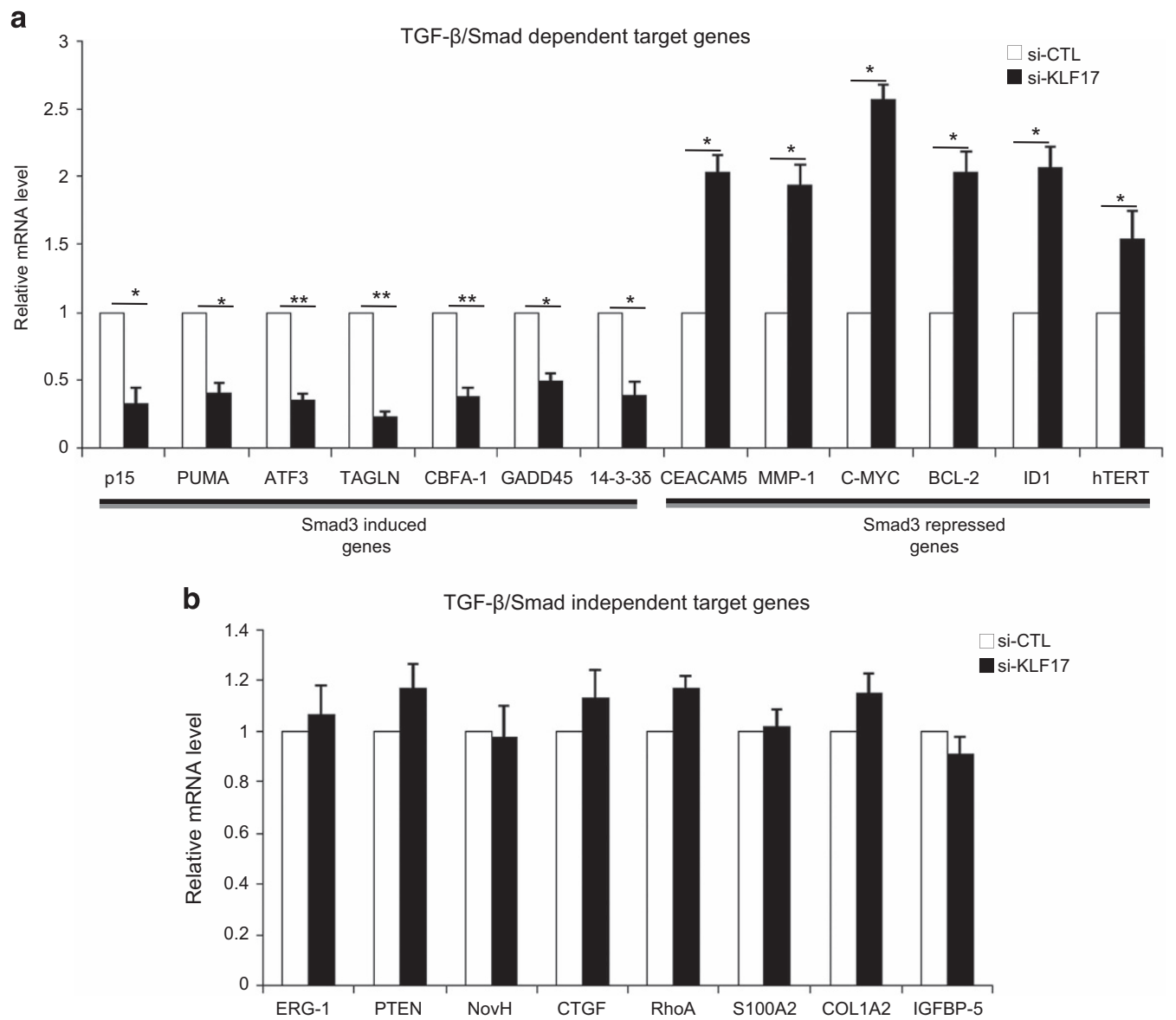

Figure 4 KLF17 regulates a panel of TGF- $\beta$-SMAD3-dependent target genes. (a and $\mathbf{b}$ ) HepG2 cells were transfected with control siRNA or siRNA targeting against KLF17 $(20 \mathrm{nM})$ for $48 \mathrm{~h}$, and analyzed by RT-PCR. Data are representative of three independent experiments (mean \pm S.D.). (Two-tailed Student's $t$-test, ${ }^{\star} P<0.05$, ${ }^{\star \star} P<0.005$ )

complexes contained both KLF17 and Smad3 proteins. Taken together, these data indicate that Smad3 and KLF17 cooperate with each other via the KLF17RE/SBE region, and simultaneously control the expression of these genes.

KLF17 inhibits proliferation in cancer cells. To investigate the physiological function of KLF17 on cytostatic behavior in cancer cells, we measured cell growth capacity with manipulated expression of KLF17. 3-(4,5-dimethylthiazol2-yl)-2,5-diphenyltetrazolium bromide (MTT) assays showed that KLF17-depleted cell lines were much more proliferated as compared with control cells (Figure 6a and Supplementary Figure 6B), indicating that KLF17 inhibits cell growth. Moreover, depletion of KLF17 attenuated DNA content in GO/G1 phase, enhanced S (DNA synthesis) and G2/M phases (Figure 6b). In contrast, overexpression of KLF17 induced the cell cycle resting phase GO/G1, decreased $S$ and G2/M phases to reduce DNA synthesis (Figure $6 c$ ), indicating a dramatic impact on cell cycle progression.

Regulation of cell growth by KLF17 may have significant impact on cancer chemotherapy. To test this, we treated the control HepG2 or KLF17 knockdown cells with cisplatin, an anti-cancer drug, followed by MTT assays. Compared with control cells, KLF17-depleted cell lines were less sensitive to anti-cancer drug treatment (Figure $6 \mathrm{~d}$ and Supplementary
Figure 5A). Conversely, we examined the effect of KLF7 overexpression on cell response to cisplatin treatment. Either overexpression of KLF17 or cisplatin treatment reduced cell proliferation, while combination of KLF17 overexpression and cisplatin application further inhibited cell growth (Figure 6e). To understand the effect of KLF17 on cellular sensitivity to cisplatin-induced cell death, we knocked down KLF17 in HepG2 cells followed by cell cycle analysis of sub-G0/1 population, in the presence or absence of cisplatin. FACS analysis showed that HepG2 cells were less susceptible to cisplatin-induced apoptosis when KLF17 was depleted (Figure 6f), suggesting that KLF17 may increase cellular sensitivity to anti-cancer chemotherapy. Furthermore, we examined the level of Poly (ADP-ribose) polymerase (PARP) cleavage. Knockdown of KLF17 decreased apoptotic levels as indicated by reduced PARP cleavage (an apoptotic marker) (Figure $6 \mathrm{~g}$ ). In contrast, overexpression of KLF17 enhanced apoptotic level in HepG2 liver cancer cells (Figure 6h).

KLF17 is critical for effective TGF- $\beta / S m a d 3$ function. Next, we aimed to address the impact of KLF17 regulation on cellular response to TGF- $\beta$ activation. HepG2 cells treated with a control or a specific small interference RNA (siRNA) against KLF17 were measured for growth inhibition by TGF- $\beta$. KLF17-depleted cells were less sensitive to TGF- $\beta$ treatment 

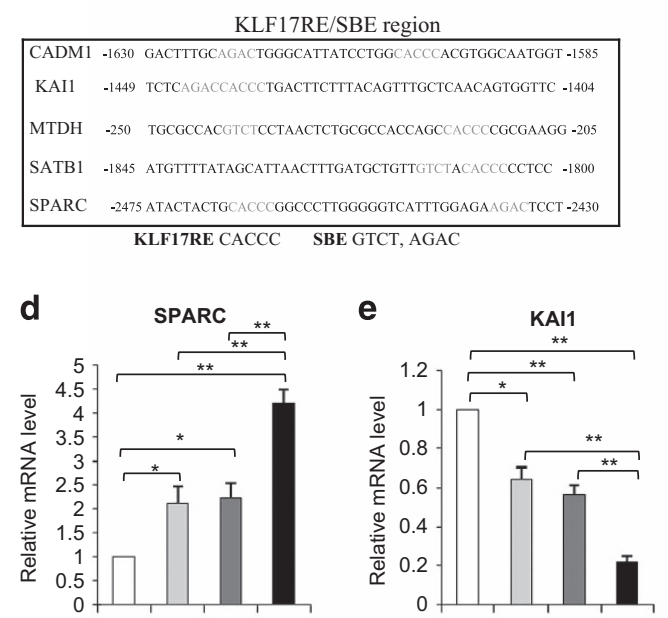

b

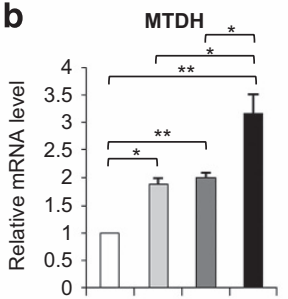

f

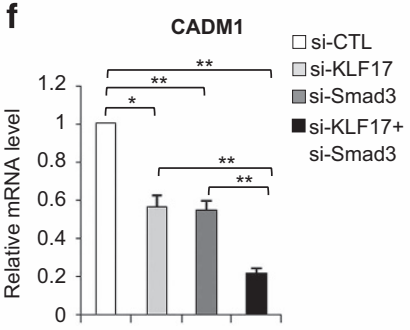

h
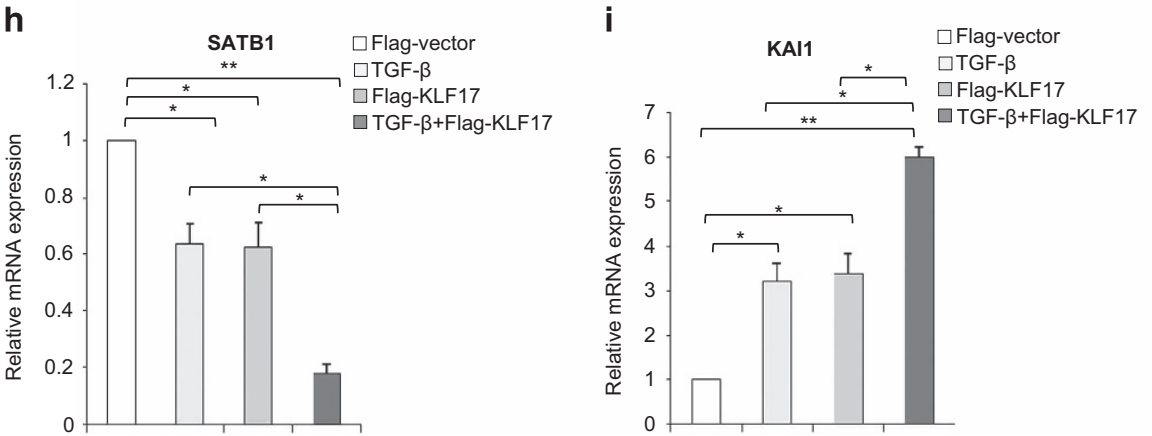
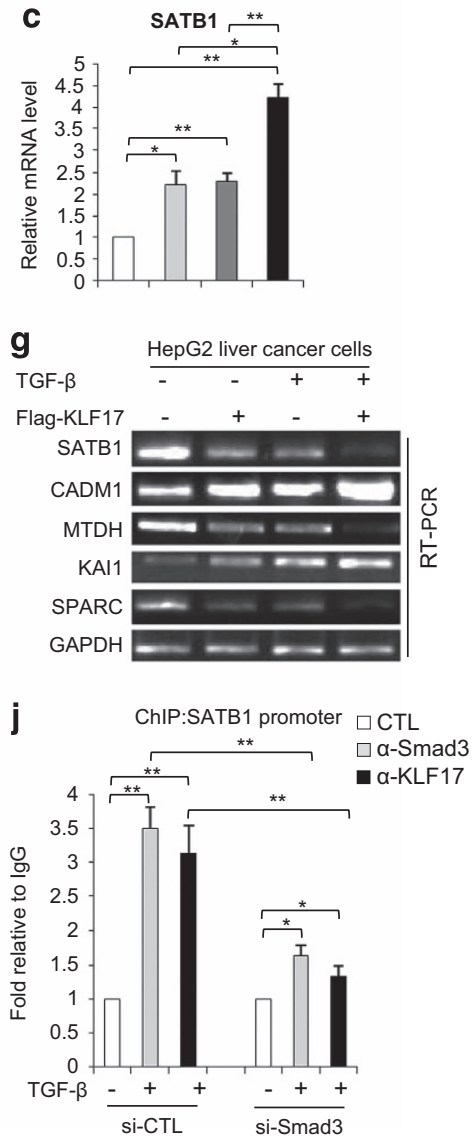

Figure 5 Cross-talk between KLF17 and SMAD3 on a subset of metastasis-associated genes (a) Schematic representation of adjacent KLF17BS and SBE region on a subset of metastasis-associated genes within 50 bp. (b-f) HepG2 cells were transfected with siRNAs targeting against Smad3 (20 nM) and KLF17 (20 nM) either independently or in combination for $48 \mathrm{~h}$ and then subjected to RT-PCR analysis. Data are representative of three independent experiments with mean \pm S.D. (two-tailed Student's $t$-test, ${ }^{*} P<0.05$, $\left.{ }^{* \star} P<0.005\right)$. (g-i) HepG2 cells were transfected with an expression plasmid encoding KLF17 and left untreated or treated with $5 \mathrm{ng} / \mathrm{ml}$ TGF- $\beta$, and subjected to semi-quantitative RT-PCR. (j) HepG2 cells were transfected with siRNA targeting against Smad3 $(20 \mathrm{nM})$ and then left untreated or treated with $5 \mathrm{ng} / \mathrm{ml}$ TGF- $\beta$ for $24 \mathrm{~h}$ and subjected to ChIP analysis with indicated antibodies. Data are representative of three independent experiments with mean \pm S.D. (two-tailed Student's $t$-test, ${ }^{*} P<0.05,{ }^{* *} P<0.005$ )

and more proliferative in comparison with control cells (Figure 7a). Furthermore, knockdown of KLF17 or Smad3 alone almost equally enhanced cell growth (Figure 7b). Cosilencing of KLF17 and Smad3 further induced cell proliferation (Figure 7b), suggesting that KLF17 might have interplay with Smad3 signaling in the inhibition of cell growth.

TGF- $\beta$ signaling is known to regulate cellular apoptosis and cell cycle progression, ${ }^{16-18}$ therefore we tested the influence of KLF17 on these TGF- $\beta$-dependent functions. Knockdown or overexpression of KLF17 affected the apoptotic levels of HepG2 cells in response to TGF- $\beta$ (Figures 7c and d), suggesting a dramatic effect of KLF17 on TGF- $\beta$-mediated control over cell death. Moreover, depletion of KLF17 attenuated the effect of TGF- $\beta$ on cell cycle progression, showing enhanced $S$ and $\mathrm{G} 2 / \mathrm{M}$ phases when compared with controls (TGF- $\beta$ treatment alone) with combination of TGF- $\beta$ and siKLF17 treatments (Figure 7e).

KLF17 expression correlates with Smad3 in cancer cells. Next, we examined KLF17 RNA expression in several human cancer cell lines. In contrast to Smad-inactive (HCT116) and Smad4 null (MDA-MB-468) cancer cell lines, ${ }^{41}$ we observed higher levels of KLF17 in Smadexpressing cells such as HepG2, MCF-7, HaCaT and H1299 (Figure 8a). We obtained similar results for their protein levels by Western blot analysis (Figure $8 b$ ).

To determine the physiopathological relevance of KLF17 with human cancer development, we analyzed clinical data to see whether KLF17 expression correlated with disease progression in human HCC. A comparison of KLF17 expression levels among normal tissues and HCC cancer samples at various stages was performed according to the Oncomine database www.oncomine.org, which provides published data sets on gene expression in cancers. Results from GSE6764 data set showed that KLF17 is significantly downregulated during cirrhosis and HCC progression (Figure 8c). Importantly, we observed an inverse correlation between KLF17 expression and HCC tumor grades (Figure $8 \mathrm{c}$ ), suggesting that decreased expression of KL17 may be associated with poor prognosis.

Moreover, we performed computational analysis to understand the correlation between KLF17 and Smad3 expressions in lung cancer data sets and found that these two tumor-suppressor proteins had strong positive correlation 


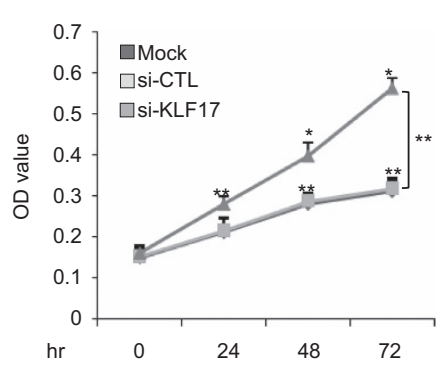

d
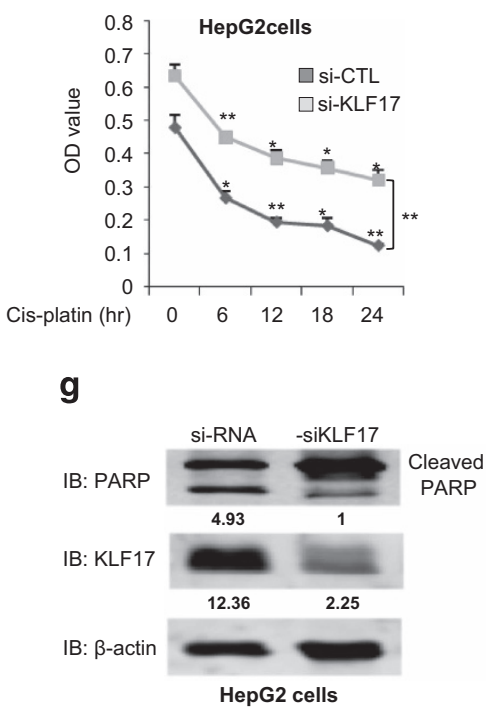

b

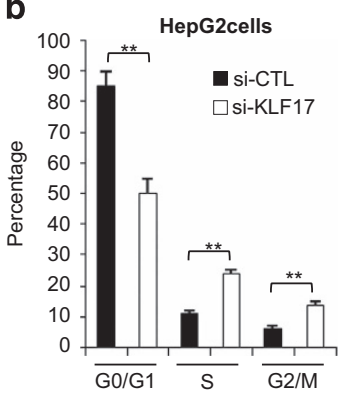

e

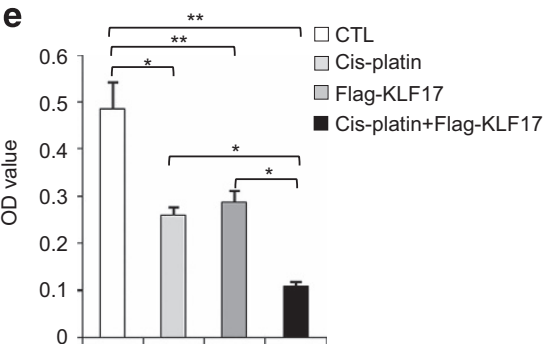

h

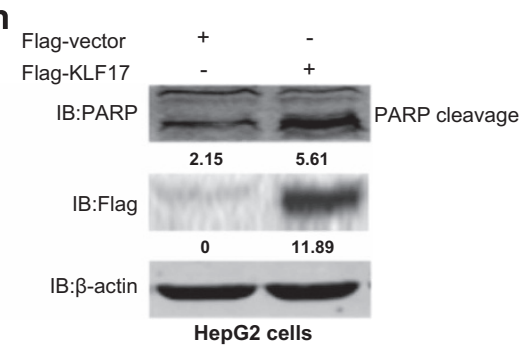

C

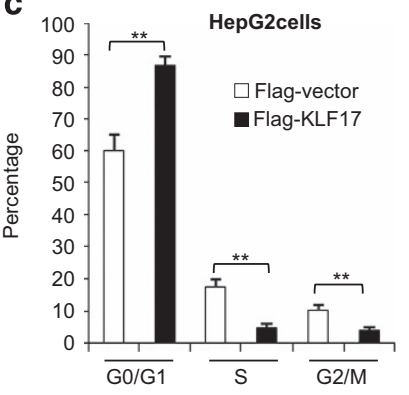

f

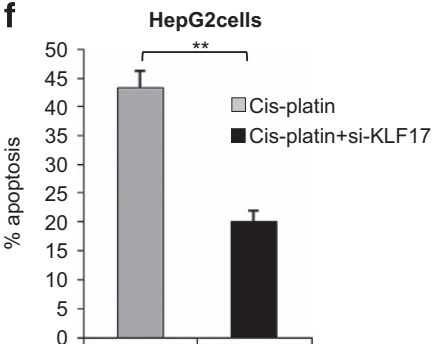

Figure 6 Knockdown of KLF17 affects multiple cellular functions. (a) HepG2 cells were transfected with control siRNA or siRNA targeting against KLF17 (20 nM) for indicated time points and subjected to MTTanalysis. Data are representative of three independent experiments with mean \pm S.D. (two-tailed Student's $t$-test, ${ }^{*} P<0.05$, ${ }^{\star} P<0.005$ ). (Two way ANOVA, $\left.{ }^{* *} P<0.005\right)$. (b) HepG2 cells were transfected with control siRNA or siRNA targeting against KLF17 (20 nM) for $72 \mathrm{~h}$ and subjected to FACS analysis. Data are representative of three independent experiments with mean \pm S.D. (two-tailed Student's $t$-test, ${ }^{*} P<0.05$, ${ }^{*} P<0.005$ ). (c) HepG2 cells were transfected with either flag vector or expression plasmid encoding KLF17 for $24 \mathrm{~h}$ and subjected to FACS analysis. Data are representative of three independent experiments (mean \pm S.D.). (two-tailed Student's t-test, $\left.{ }^{\star} P<0.05,{ }^{\star}{ }^{\star} P<0.005\right)$. (d) HepG2 cells were transfected with control siRNA or siRNA targeting against KLF17 (20 nM) for $48 \mathrm{~h}$ and then left untreated or treated with cisplatin for indicated time points and subjected to MTT analysis. Data are representative of three independent experiments with mean \pm S.D. (two-tailed Student's $t$-test, ${ }^{\star} P<0.05,{ }^{*} P<0.005$ ). (two way ANOVA, ${ }^{*} P<0.005$ ). (e) HepG2 cells were transfected with either flag vector or an expression plasmid encoding KLF17 and left untreated or treated with cisplatin for $12 \mathrm{~h}$ and subjected to MTT analysis. Data are representative of three independent experiments (mean \pm S.D.). (two-tailed Student's $t$-test, ${ }^{*} P<0.05$, $\left.{ }^{* \star} P<0.005\right)$. (f) HepG2 cells were transfected with control siRNA or siRNA targeting against KLF17 (20 nM) and then left untreated or treated with cisplatin ( $5 \mu$ M) and subjected to FACS analysis to determine the apoptotic level. Data are representative of three independent experiments with mean \pm S.D. (Two-tailed Student's $t$-test, ${ }^{\star} P<0.05$, $\left.{ }^{* *} P<0.005\right)$. (g) HepG2 cells were transfected with control siRNA or siRNA targeting against KLF17 (20 nM) for $72 \mathrm{~h}$ and subjected to immunoblot analysis with indicated antibodies. (h) HepG2 cells were transfected with either flag vector or expression plasmid encoding KLF17 for $24 \mathrm{~h}$ and subjected to immunoblot analysis with indicated antibodies

with each other in lung cancers (Figure 8d and Supplementary Figure 6), consistent with the molecular basis of regulatory features in KLF17 and Smad3 identified above.

To further substantiate the biological relevance of our findings about mutual regulation of KLF17 and Smad3 in tumor development, we evaluated the correlation between Smad3 and KLF17 expression by IHC analysis using liver, breast and intestinal cancer tissues in a total of 17 cases with adjacent 'non-tumor' controls. Interestingly, KLF17 expression was strongly correlated with Smad3 level in all tested cancer samples except 1 (Figure 8e, labeled as KLF17+ and Smad3+, and Supplementary Fig. 7). Among the highly correlated cancer samples, two displayed low levels of KLF17 and Smad3 expression (Figure 8e, KLF17 - and Smad3 - ).

\section{Discussion}

Cancer metastasis is a complex process that involves numerous critical and influential molecules/proteins. Among these important factors KLF17 has ability to inhibit metastasis and EMT. However, the molecular details that how KLF17 control cancer metastasis remains unclear. In this study, we provide new insights into the anti-metastasis and tumor suppressive function of KLF17. We indentified that KLF17 has a key role to potentiate TGF- $\beta /$ Smad-dependent pathway to suppress cancer progression. Our finding, suggest that KLF17 is one of the key regulator of TGF- $\beta /$ Smad-dependent pathway. Our results indicate that loss of KLF17 impairs tumor suppressive function of TGF- $\beta /$ Smad-dependent pathway. Moreover, in this report, we investigated a previously unknown regulatory mechanism for the regulation of KLF17 by 


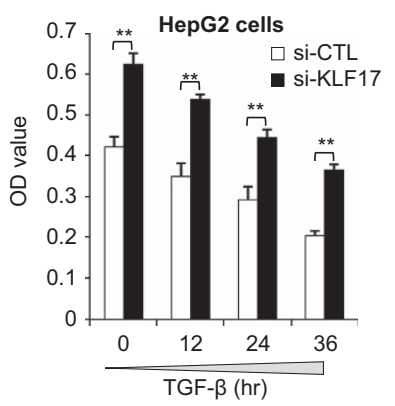

d

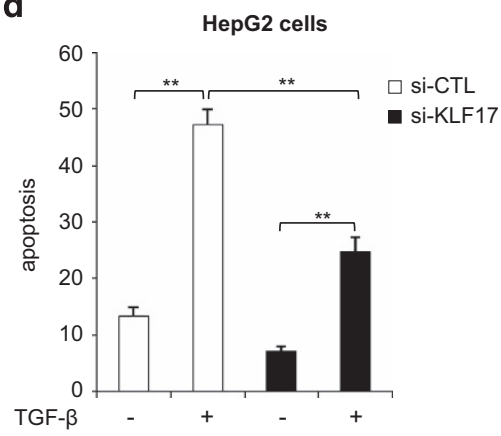

a b

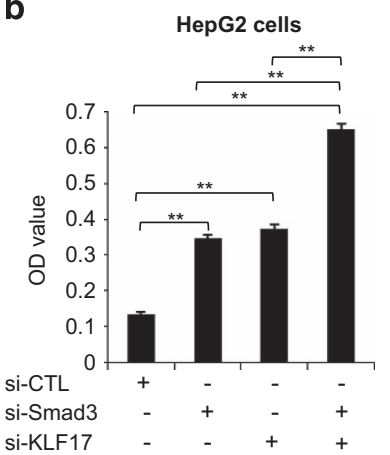

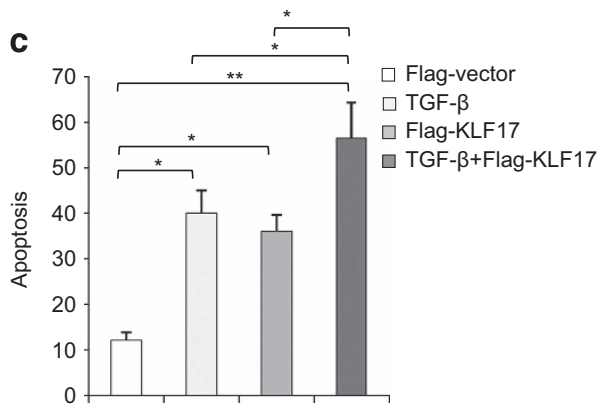

e

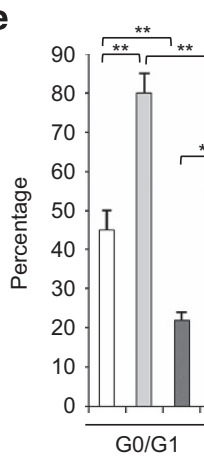

HepG2 cells

Figure 7 KLF17 is important for tumor suppressive function of TGF- $\beta$ ISMAD3 pathway. (a) HepG2 cells were transfected with control siRNA or siRNA targeting against KLF17 (20 nM) for $48 \mathrm{~h}$ and then left untreated or treated with $5 \mathrm{ng} / \mathrm{ml}$ TGF- $\beta$ for indicated time points and MTT assay was performed. Data are representative of three independent experiments with mean \pm S.D. (two-tailed Student's $t$-test, $\left.{ }^{*} P<0.05,{ }^{* \star} P<0.005\right)$. (b) HepG2 cells were transfected with siRNAs targeting against Smad3 (20 nM) and KLF17 (20 nM) either independently or in combination for $72 \mathrm{~h}$ and then subjected to MTT analysis. Data are representative of three independent experiments with mean \pm S.D. (two-tailed Student's $t$-test, ${ }^{*} P<0.05,{ }^{* *} P<0.005$ ). (c) HepG2 cells were transfected either with flag vector or expression plasmid encoding KLF17 and then left untreated or treated with $5 \mathrm{ng} / \mathrm{ml}$ TGF- $\beta$ and subjected to FACS analysis to detect apoptotic level. Data are representative of three independent experiments (mean \pm S.D.). (Two-tailed Student's $t$-test, ${ }^{*} P<0.05,{ }^{*} P<0.005$ ). (d) HepG2 cells were transfected with control siRNA or siRNA targeting against KLF17 (20 nM) for $48 \mathrm{~h}$ and then left untreated or treated with $5 \mathrm{ng} / \mathrm{ml} \mathrm{TGF-} \beta$ for $24 \mathrm{~h}$ and FACS analysis was performed to detect the apoptotic level. Data are representative of three independent experiments with mean \pm S.D. (two-tailed Student's t-test, ${ }^{*} P<0.05,{ }^{* *} P<0.005$ ). (e) HepG2 cells were transfected with control siRNA or siRNA targeting against KLF17 (20 nM) for $48 \mathrm{~h}$ and then left untreated or treated with $5 \mathrm{ng} / \mathrm{ml}$ TGF- $\beta$ for $24 \mathrm{~h}$ and FACS analysis was performed to detect the cell cycle progression. Data are representative of three independent experiments with mean \pm S.D. (two-tailed Student's $t$-test, ${ }^{\star} P<0.05,{ }^{*} P<0.005$ )

TGF- $\beta /$ Smad3 signaling in cancer cells. It is generally believed that the Smad-dependent pathway is involved in TGF- $\beta$ tumor suppressive functions at an early stage of cancer development, whereas activation of Smad-independent pathways is coupled with the loss of tumor-suppressor function of TGF- $\beta$, which is important for its pro-oncogenic effects. ${ }^{30}$ TGF- $\beta$ enhances the protein level of KLF17 in multiple cancer cell lines. Thus, induction of KLF17 by TGF- $\beta /$ Smad3 may be one of the mechanisms to fight against cancer development.

We show that KLF17 is required for the full transcriptional activity of TGF- $\beta /$ Smad3 signaling. In our search for the molecular mechanisms by which KLF17 affects the TGF- $\beta$ / Smad signaling, we have found that KLF17 induces Smad3 transcription in cultured cells, indicating novel autoregulatory positive feedback loop with Smad3 (Figure 9). Due to this regulation, depletion of KLF17 decreases the recruitment of Smad3 to its target gene promoters by reduced SBE/DNASmad complex formation. In fact, activated Smad3 and KLF17 mutually affect each other transcriptionally to inhibit cell proliferative effects. Thus, a possible significance of this loop is that both proteins can cooperatively enhance the transcription of target genes in cancer cells to overcome cancer progression.
We also found a novel cross-talk between Smad3 and KLF17 on a subset of metastasis-associated genes in HepG2 cells. The combinational loss of Smad3 and KLF17 function can significantly change the expression of these metastasis genes. Both KLF17 and Smad3 interact with the KLF17RE/ SBE region and form a transcription complex in a TGF- $\beta$ dependent manner. Thus, combinatorial control of gene expression by KLF17-Smad3 pathways provides a new tier in regulation of TGF- $\beta$ responsive genes. Our mechanistic study provides an insight to the well-known observation that both KLF17 and TGF- $\beta /$ Smad3 can regulate ID1 and impinge on cancer cell metastasis. ${ }^{9}$

In addition to cytostatic effect, KLF17 is also critical for tumor-suppressor function of TGF- $\beta$ in regulating cell cycle and cell death. Depletion of KLF17 attenuates cellular response to TGF- $\beta$-mediated inhibition of cell cycle progression and induction of cell apoptosis, which may contribute to enhanced chemoresistance in cultured cell. Furthermore, we show that KLF17 increases the sensitivity of cancer cells response to anti-cancer drugs. All our results highlight a tight association between KLF17 and TGF- $\beta /$ Smad tumor suppressive functions and are endorsed by other publications that reduced KLF17 is potentially associated with advanced 
a

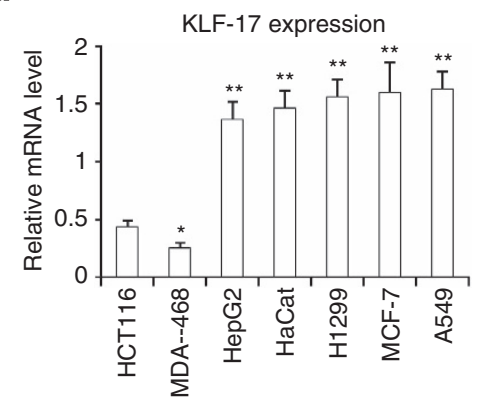

b

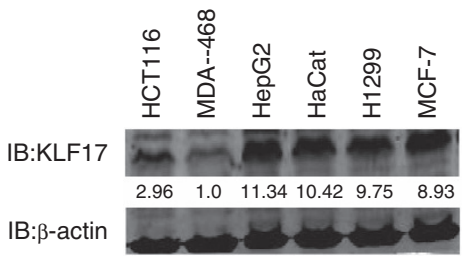

C

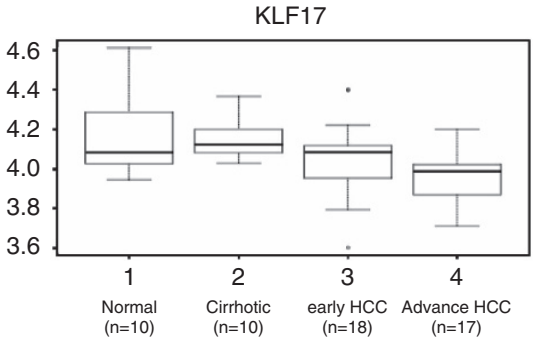

e

Liver Cancer

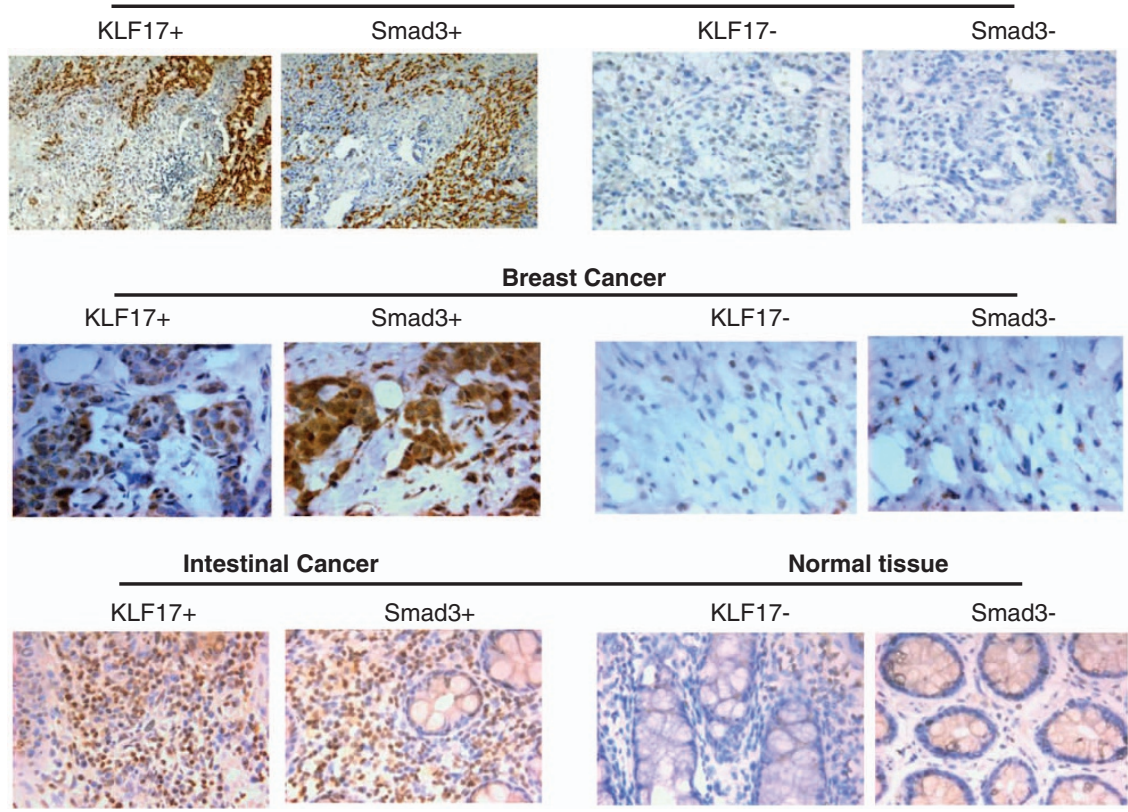

Figure 8 Correlation of SMAD3 and KLF17 expression in multiple cancer cells (a) KLF17 expression in multiple cancer cell lines was detected by RT-PCR. Data are representative of three independent experiments with mean \pm S.D. (two-tailed Student's $t$-test, ${ }^{*} P<0.05,{ }^{*} P<0.005$ ). (b) KLF17 expression in multiple cancer cell lines was detected by immunoblot analysis. (c) Inverse correlation between KLF17 expression and tumor stages in human liver cancer. Data and statistics were obtained from GEO data base. (d) Bioinformatics analysis of Lung cancer data set in which Smad3 expression is positively correlated with KLF17. Pearson's correlation coefficient was used as a measure of correlation between Smad3 and KLF17. Pearson's correlation analysis was conducted using 'R program' on data set obtained from http://www.ncbi.nlm.nih.gov/geo/. (e) IHC analysis between Smad3 and KLF17 in liver $(n=2)$, breast $(n=9)$ and intestinal cancer $(n=6)$, respectively

cancer progression. $^{6-9}$ Thus, cancer patients with higher levels of KLF17 may benefit from treatment with chemotherapeutic agents.

Finally, our study indicates that targeting KLF17 for cancer therapy may be beneficial for some human tumors having abnormal Smad3 proteins. For instance, Smad3 inactivation is known to accelerate cancer metastasis. ${ }^{42-46}$ Given the complicated roles of TGF- $\beta$ pathway in the regulation of cancer metastasis, ${ }^{47,48}$ it remains unclear whether KLF17 may cooperatively or discordantly affect TGF- $\beta$ signaling in different tumor metastasis. These findings are the first evidence for the cross-talks over TGF- $\beta$-Smad3-KLF17 pathways. Even though growing evidence suggests that KLF17 is involved in the inhibition of metastasis and EMT, great efforts are still needed to further understand KLF17 regulation during cancer progression.

\section{Materials and Methods}

Plasmids and transfection. pcDNA3.1-KLF17 was constructed. While, pRK5-Smad3 and pRK5-Smad4 were kindly provided by Dr. Xin Hua Feng, Baylor
College of Medicine. HepG2 cell lines were transfected with Lipofectamine 2000 following manufacturer's protocol (Invitrogen, Life Technologies, Carlsbad, CA, USA).

Antibodies. Following antibodies were used in Western Blot, EMSA and ChIP experiments: anti-Smad3 (Cell Signaling Technology, Danvers, MA, USA), antiSmad4 (Santa Cruz Biotechnology, Dallas, TX, USA), anti- $\beta$ actin (Santa Cruz Biotechnology), anti-AcH4 (Millipore, Temecula, CA, USA), anti-KLF17 (Abcam, Cambridge, UK).

Cell culture and treatments. HaCaT, MCF-7, HepG2 and A549 were purchased from American Type Culture Collection (ATCC, Manassas, VA, USA). For cells treatments, we used $5 \mathrm{ng} / \mathrm{ml}$ TGF- $\beta 1$ (R\&D Systems, Minneapolis, MN, USA) and $5 \mu \mathrm{g} / \mathrm{ml}$ of cisplatin (Sigma-Aldrich, St. Louis, MO, USA).

Electrophoretic mobility shift assay. EMSA was performed as described previously..$^{30}$ Briefly, EMSA was performed with ${ }^{32} \mathrm{P}$-radiolabeled probes. About $2 \mu \mathrm{g}$ of nuclear extract or different concentration of purified proteins was incubated with ${ }^{32} \mathrm{P}$-radiolabeled-probes in $20 \mu \mathrm{l}$ of EMSA reaction buffer $(2 \mu \mathrm{g}$ of poly $(\mathrm{dl}-\mathrm{dC})$, $20 \mathrm{mM}$ HEPES (pH 7.9), $1 \mathrm{mM} \mathrm{MgCl}, 40 \mathrm{mM} \mathrm{KCl}, 0.1 \mathrm{mM}$ EDTA, $1 \mathrm{mM}$ DTT and $12 \%$ glycerol). To perform the competition assay, excess of unlabeled competitor's oligo was added to the EMSA reaction mixture. Protein-DNA complexes were resolved in $5 \%$ polyacrylamide gels containing $0.5 \times$ TBE and exposed to 
a

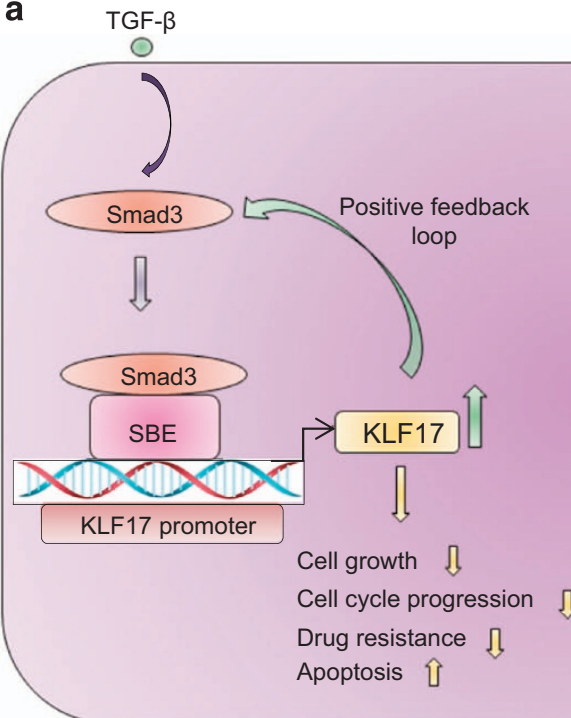

Feedback loop between Smad3 and KLF17

TGF- $\beta$

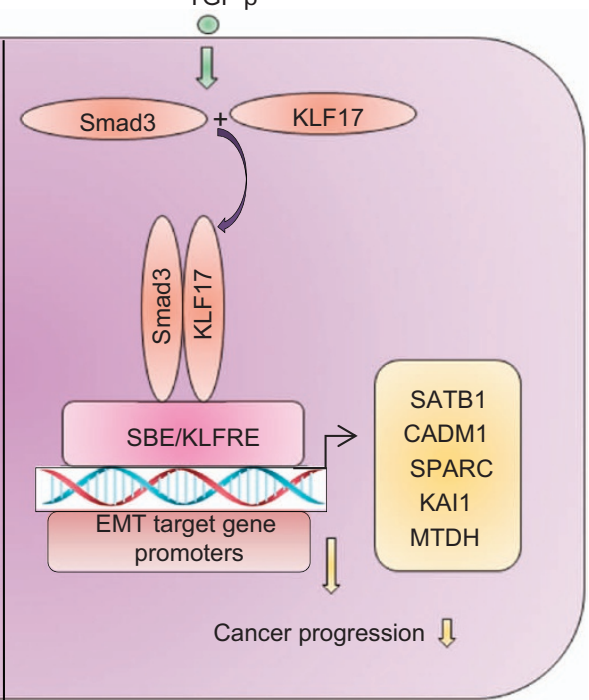

Cross talk between Smad3 and KLF17

Figure 9 A simplified model depicting (a) Novel positive feedback loop between TGF- $\beta$-SMAD3 and KLF17 in cancer cells. (b) Novel cross-talk between SMAD3- KLF17 pathways on a subset of metastasis-associated genes via KLF17RE/SBE region in cancer cells

phosphorimager (Bio-Rad Laboratories Inc., Hercules, CA, USA). For the supershift assay, nuclear extracts in EMSA reaction buffer were incubated with different antibodies for $30 \mathrm{~min}$ and probes were then added.

Chromatin immunoprecipitation assay. After treatment with TGF- $\beta$ or overexpression of KLF17, nuclear proteins were cross-linked to genomic DNA by adding formaldehyde for 10 min directly to the medium to a final concentration of $1 \%$. Cross-linking was stopped by adding glycine to a final concentration of $0.125 \mathrm{M}$ and incubating for $5 \mathrm{~min}$ at room temperature on a rocking platform. The medium was removed and the cells were washed twice with ice cold phosphate-buffered saline (PBS) $\left(140 \mathrm{mM} \mathrm{NaCl}, 2.7 \mathrm{mM} \mathrm{KCl}, 1.5 \mathrm{mM} \quad \mathrm{KH}_{2} \mathrm{PO}_{4}\right.$ and $8.1 \mathrm{mM}$ $\mathrm{Na}_{2} \mathrm{HPO}_{4} \cdot 2 \mathrm{H}_{2} \mathrm{O}$ ). The cells were collected by scraping in ice cold PBS supplemented with a protease inhibitor cocktail. After centrifugation, the cell pellets were resuspended in lysis buffer containing $1 \%$ SDS, $10 \mathrm{mM}$ EDTA, protease inhibitors and $50 \mathrm{mM}$ Tris- $\mathrm{HCl}(\mathrm{pH} 8.1)$ and the lysates were sonicated to result in DNA fragments of $\sim 200$ to $1000 \mathrm{bp}$ in length. Cellular debris was removed by centrifugation and the lysates were diluted $1: 10$ in ChIP dilution buffer $(0.01 \%$ SDS, $1.1 \%$ Triton X-100, 1.2 mM EDTA, $16.7 \mathrm{mM} \mathrm{NaCl}$, protease inhibitors and $16.7 \mathrm{mM}$ Tris- $\mathrm{HCl}(\mathrm{pH}$ 8.1)). Non-specific background was removed by incubating the chromatin resuspension with a salmon sperm DNA/protein A agarose slurry for $30 \mathrm{~min}$ at $4^{\circ} \mathrm{C}$ with agitation. The samples were centrifuged and the recovered chromatin solutions were incubated with $3-5 \mu \mathrm{g}$ of indicated antibodies overnight at $4^{\circ} \mathrm{C}$ with rotation. The immunocomplexes were collected with $60 \mu \mathrm{l}$ of protein $\mathrm{A}$ agarose slurry for $2 \mathrm{~h}$ at $4^{\circ} \mathrm{C}$ with rotation. The beads were pelleted by centrifugation for $1 \mathrm{~min}$ at $4^{\circ} \mathrm{C}$ and washed sequentially for $5 \mathrm{~min}$ by rotation with $1 \mathrm{ml}$ of the following buffers: low salt wash buffer (0.1\% SDS, $1 \%$ Triton X-100, $2 \mathrm{mM}$ EDTA, $150 \mathrm{mM} \mathrm{NaCl}$ and $20 \mathrm{mM}$ Tris-HCl $(\mathrm{pH} 8.1))$, high salt wash buffer $(0.1 \%$ SDS, $1 \%$ Triton X-100, $2 \mathrm{mM}$ EDTA, $500 \mathrm{mM} \mathrm{NaCl}$ and $20 \mathrm{mM}$ Tris- $\mathrm{HCl}(\mathrm{pH}$ 8.1)) and $\mathrm{LiCl}$ wash buffer $(0.25 \mathrm{mM} \mathrm{LiCl}, 1 \%$ Nonidet P- $40,1 \%$ sodium deoxycholate, $1 \mathrm{mM}$ EDTA and $10 \mathrm{mM}$ Tris- $\mathrm{HCl}(\mathrm{pH}$ 8.1)). Finally, the beads were washed twice with $1 \mathrm{ml}$ TE buffer ( $1 \mathrm{mM}$ EDTA and $10 \mathrm{mM}$ Tris- $\mathrm{HCl}(\mathrm{pH}$ 8.0)). The immunocomplexes were then eluted by adding $250 \mu \mathrm{l}$ elution buffer (1\% SDS and $100 \mathrm{mM} \mathrm{NaHCO}_{3}$ ) and incubation for $15 \mathrm{~min}$ at room temperature with rotation. After centrifugation, the supernatant was collected and the cross-linking was reversed by adding $\mathrm{NaCl}$ to final concentration of $200 \mathrm{mM}$ and incubating overnight at $65^{\circ} \mathrm{C}$. The remaining proteins were digested by adding proteinase $\mathrm{K}$ (final concentration $40 \mu \mathrm{g} / \mathrm{ml}$ ) and incubation for $1 \mathrm{~h}$ at $45^{\circ} \mathrm{C}$. The DNA was recovered by phenol/chloroform/isoamyl alcohol $(25: 24: 1)$ extractions and precipitated with 0.1 volumes of $3 \mathrm{M}$ sodium acetate ( $\mathrm{pH} 5.2$ ) and 2 volumes of ethanol using glycogen as a carrier. PCR amplification of the genomic-fragments was performed with specific primers flanking putative binding sites of target promoters. The PCR products were separated by electrophoresis through $2.0 \%$ agarose.
Production and purification of Smad3 fusion protein. Smad3 protein was purified as described previously. ${ }^{31}$ Full-length $S m a d 3$ protein fused to GST were expressed in Escherichia coli and partially purified by column chromatography using Pharmacia's protocol. Briefly, bacteria were grown in 2x YTA medium and induced with $0.1 \mathrm{mM} \mathrm{IPTG}$. After sonication, GST fusions were isolated using glutathione-Sepharose $4 \mathrm{~B}$, washed three times, eluted and then dialysed against PBS supplemented with $2 \mathrm{mM}$ DTT and $0.5 \mathrm{mM} \mathrm{PMSF}$

Luciferase reporter constructs. DNA fragments containing KLF17 and Smad3 genomic sequences were amplified from HepG2 cells genomic DNA using the PCR and ligated into kpn1/xhol sites of the promoterless pGL3-Basic (Promega, Madison, WI, USA) vector.

Luciferase assay. After transfection and/or treatment, the cells were washed with PBS three times. The cells were then lysed in the luciferase cell culture lysis buffer provided with the Luciferase Assay Kit (Promega). After a brief vortex, whole cell lysates were centrifuged in the cold $\left(4^{\circ} \mathrm{C}\right)$ at 12000 r.p.m. for $2 \mathrm{~min}$. Supernatant was collected in a fresh tube and $20-30 \mathrm{ml}$ of that was added to luciferase assay substrate $(60-80 \mathrm{ml})$. Luminescence was measured as relative light units, twice for each lysate, taking the reading of luciferase assay using a LUMlstar OPTIMA, BMG LABTECH Inc. (Cary, NC, USA). Each assay was repeated for three times. Fold repression values were represented as mean of the three independent experiments.

Nuclear extracts preparation. Cells from 100-mm dishes were washed with PBS and scraped. After another washing, cells were suspended in $2 \mathrm{ml}$ of cold buffer A (20 mM HEPES pH 7.9, $20 \mathrm{mM} \mathrm{NaF}, 1 \mathrm{mM} \mathrm{Na}_{3} \mathrm{VO}_{4}, 1 \mathrm{mM} \mathrm{Na} \mathrm{P}_{2} \mathrm{O}_{7}$, $0.13 \mu \mathrm{M}$ okadaic acid, $1 \mathrm{mM}$ EDTA, $1 \mathrm{mM}$ EGTA, $0.4 \mathrm{mM}$ ammonium molybdate, $1 \mathrm{mM}$ DTT, $0.5 \mathrm{mM}$ PMSF and $1 \mu \mathrm{g} / \mathrm{ml}$ each leupeptin, aprotinin and pepstatin). Cells were allowed to swell on ice for $15 \mathrm{~min}$ and then lysed by 30 strokes of a Dounce all-glass homogenizer (Thomas Scientific, Swedesboro, NJ, USA). Nuclei were pelleted by centrifugation and resuspended in $600 \mu \mathrm{l}$ of cold buffer $\mathrm{C}$ (buffer $\mathrm{A}$, $420 \mathrm{mM} \mathrm{NaCl}$ and $20 \%$ glycerol). The nuclear membrane was lysed by 15 strokes of a Dounce all-glass homogenizer. The resulting suspension was stirred for $30 \mathrm{~min}$ at $4{ }^{\circ} \mathrm{C}$. The clear supernatant was aliquoted and frozen at $-80^{\circ} \mathrm{C}$.

RNA Interference. Cells were cultured to $30 \%$ confluence. For each well in a six-well culture dish, $20 \mathrm{nM}$ of Smad3-KLF17 siRNAs, or appropriate negative control siRNAs, were transfected into cells using Lipofectamine 2000 following manufacturer's protocol. Cells were incubated at $37^{\circ} \mathrm{C}$ in a $\mathrm{CO} 2$ incubator, and $6-8 \mathrm{~h}$ later $10 \%$ serum growth medium was added to the transfection mixture. Cell extracts were assayed by Western blot for Smad3-KLF17 protein expression at $72 \mathrm{~h}$ 
post transfection, while for mRNA expression at $48 \mathrm{~h}$ after transfection. Please see the Supplementary Information for primer sequences.

Real time-PCR. Total RNA from cells was isolated using TRIZOL (Invitrogen, Life Technologies) following manufacturer's protocol. Briefly, $0.5-1 \mu \mathrm{g}$ of total RNA was reverse transcribed in a total volume of $25 \mu$ l, including $132 \mathrm{U}$ of Moloneymurine-leukemia virus reverse transcriptase, $26.4 \mathrm{U}$ of RNAase inhibitor, $0.6 \mu \mathrm{g}$ of (dT) 15 primer, $2 \mu \mathrm{M}$ dNTPs and 1x Moloney-murine-leukemia virus RT buffer provided by Promega. Aliquots of the RT products were used for RT-PCR analysis. For semi qRT-PCR, $2 \mu$ l of RT products was brought to a volume of $25 \mu$ l containing $1.5 \mathrm{mM} \mathrm{MgCl} 2,0.25 \mathrm{mM}$ of each dNTPs, $0.5 \mu \mathrm{M}$ of both the upstream and downstream PCR primers, and $1 \mathrm{x}$ Taq Reaction-Buffer and $1.25 \mathrm{U}$ of Taq DNA polymerase provided by Promega. PCR products were visualized by electrophoresis on a $2 \%$ agarose gel in $0.5 \times$ TBE buffer after staining with $0.5 \mu \mathrm{g} / \mathrm{ml}$ ethidium bromide. For qRT-PCR, $2 \mu$ l of reverse transcribed CDNA was subjected to RT-PCR using mastermix with SYBR green (Bio-Rad Laboratories Inc.) and the Mx3005Pquantitative RT-PCR system (Stratagene, Amsterdam, Netherlands). Each reaction consisted SYBR green (1:60000 final concentration), $40 \mathrm{nM}$ of both sense and antisense primers, $2 \mu \mathrm{l}$ of $\mathrm{CDNA}$ and $\mathrm{H} 2 \mathrm{O}$ to a final volume of $20 \mu \mathrm{l}$. Each experiment was performed in duplicates, and repeated thrice.

Preparation of total cell extract and Western blot analysis. Cells were washed with PBS and treated with an extraction buffer $(50 \mathrm{mM}$ Tris- $\mathrm{HCl}, \mathrm{pH}$ $7.4,1 \%$ Nonidet P-40, 0.25\% sodium deoxycholate, $150 \mathrm{mM} \mathrm{NaCl}$ and $1 \mathrm{mM}$ EDTA) supplemented with $1 \mathrm{mM}$ phenylmethanesulfonyl fluoride, $1 \mathrm{mM}$ sodium orthovanadate (Na3VO4), $0.1 \mathrm{mM}$ dithiothreitol, $0.4 \mu \mathrm{g} / \mathrm{ml}$ leupeptin/pepstatin. Cell extract was stored at $-20^{\circ} \mathrm{C}$ until required. Protein samples were subject to electrophoresis in 10\% SDS polyacrylamide-gel. Separated proteins were electroblotted to Nitrocellulose membranes (Bio-Rad Laboratories Inc.), and blot was blocked for $1 \mathrm{~h}$ at room temperature with blocking buffer $0.1 \%$ PBST with $5 \%$ fat-free dried milk powder. Blot was then incubated with primary antibodies, (1: 1000 dilutions) at $4{ }^{\circ} \mathrm{C}$ overnight. Blot was washed with $0.1 \%$ TBST three times, and incubated with secondary antibodies (mouse, rabbit; $1: 5000$ dilution) for $1 \mathrm{~h}$. Blot was washed again three times and exposed to Odyssey LI-COR-scanner (LI-COR Biotechnology, Lincoln, NE, USA).

MTT assay. Cell viability was assessed with a MTT assay in replicates. Cells were seeded in 96-well plate at $2.5 \times 10^{3}$ cells/well, and incubated in $10 \%$ FBS supplemented with DMEM for $24 \mathrm{~h}$. After that cells were treated with etoposide/ TGF- $\beta$ for indicated time points. Controls received DMSO vehicle at a concentration equal to that in drug-treated cells. After that drug containing medium was replaced with $200 \mu \mathrm{l}$ of $10 \%$ FBS supplemented with DMEM containing $0.5 \mathrm{mg} / \mathrm{ml} \mathrm{MTT}$, and cells were incubated in the $\mathrm{CO}_{2}$ incubator at $37^{\circ} \mathrm{C}$ for $2 \mathrm{~h}$, and absorbance $(490 \mathrm{~nm})$ was measured and analyzed (Mississauga, ON, Canada).

Cell cycle analysis. Cell cycle analysis was carried out by estimating DNA contents with flow cytometry. Cells were fixed in ice cold $70 \%$ ethanol, incubated overnight at $-20{ }^{\circ} \mathrm{C}$ and stained with propidium iodide/Triton X-100 containing RNaseA solution (Shanghai Promega Biological Products, Ltd., Shanghai, China) for $15 \mathrm{~min}$ at $37^{\circ} \mathrm{C}$. Cell cycle analysis was performed using BD Cantoll cell analyzer (Mississauga, ON, Canada).

Bioinformatics analysis. Microarray data sets were analyzed by arrayQualityMetrics, affyQCReport and affy packages from bioconductor (http://www. bioconductor.org/) with $\mathrm{R}$ (http://www.r-project.org/). First, all raw data were downloaded from NCBI Gene Expression Omnibus (GEO, http://www.ncbi.nlm.nih. gov/geo) database (ID:GSE6764). Second, 55 samples were chosen from the data sets and grouped into 4 classes, namely normal samples $(n=10)$, cirrhotic patients $(n=10)$, early HCC patients (including very early HCC, $n=18$ ) and advanced HCC patients (including very advanced HCC, $n=17$ ). The data were normalized by robust multi-array average expression measure depending on affy packages in $\mathrm{R}$. The log2 ratio gene expression values were calculated based on the normalized data.

Immunohistochemsitry. Paraffin-embedded sections (3- $\mu \mathrm{m}$ thick) of different tumors and adjacent normal tissues were used to perform IHC reaction. Tissue section were de-paraffined with xylene and dehydrated with sequential washes of 100, 95 and $70 \%$ ethanol. Endogenous peroxidase activity was quenched using $0.3 \%$ hydrogen peroxide in methanol for $30 \mathrm{~min}$ and then washed in PBS. Antigen retrieval was achieved using a pressure boiler heating in retrieval solution, $\mathrm{pH} 6$, at $125^{\circ} \mathrm{C}$ for $4 \mathrm{~min}$, followed by a 20 -min cool down period at room temperature. Slides were then incubated with anti-Smad3 and anti-KLF17 antibodies at $4{ }^{\circ} \mathrm{C}$ overnight. Then the slides were rinsed three times in PBS and incubated in biotinlabeled rabbit anti-rabbit secondary antibodies for $1 \mathrm{~h}$ at room temperature. After washing three times with PBS, the staining was performed using 3, 3'diaminobenzidine. Sections were counterstained with hematoxylin. We also compared IHC data between tumors and corresponding adjacent normal tissues by percentage of intensity of staining to estimate the changes between Smad3 and KLF17.

\section{Conflict of Interest}

The authors declare no conflict of interest.

Acknowledgements. This study was funded by the National Basic Research Program (2011CB504200), This work was supported in part by a joint China-Canada grant from the National Natural Science Foundation of China Grants (81261120555). This work was also supported by the National Natural Science Foundation of China Grants (31200878), the Shanghai natural science foundation (12ZR1409300) and the Applied Basic Research Program of Science and Technology Department of Sichuan Province (2015JY0038).

\section{Author contributions}

$A A, Y L, S W$ and $H W$ performed the experiments; $X L, P Z, Y D$ and JX designed the project; XL, RM, DW, X-HF and AA wrote the manuscript.

1. Ferlay J, Shin HR, Bray F, Forman D, Mathers C, Parkin DM et al. Estimates of worldwide burden of cancer in 2008. Int J Cancer 2008; 127: 2893-2917.

2. Jemal A, Bray F, Center MM, Ferlay J, Ward E, Forman D et al. Global cancer statistics. CA Cancer J Clin 2011; 61: 69-90.

3. Sun Z, Meng C, Wang S, Zhou N, Guan M, Bai C et al. MicroRNA-1246 enhances migration and invasion through CADM1 in hepatocellular carcinoma. BMC Cancer 2014; 27: 616

4. Suske G, Bruford E, Philipsen S. Mammalian SP/KLF transcription factors: bring in the family. Genomics 2005; 85: 551-556.

5. Black AR, Black JD, Azizkhan-Clifford J. Sp1 and krüppel-like factor family of transcription factors in cell growth regulation and cancer. J Cell Physiol 2001; 188: 143-160.

6. Moore DL, Blackmore MG, Hu Y, Kaestner KH, Bixby JL, Lemmon VP et al. KLF family members regulate intrinsic axon regeneration ability. Science 2009; 326: 298-301.

7. Marie PT, Yizeng Y, Jonathan PK. Krüppel-like factors in cancer. Nat Rev Cancer 2013; 13: $701-713$

8. James JB. Krüppel-like factors: three fingers in many pies. J Biol Chem 2001; 276: 34355-34358.

9. Gumireddy K, Li A, Gimotty PA, Klein-Szanto AJ, Showe LC, Katsaros D et al. KLF17 is a negative regulator of epithelial-mesenchymal transition and metastasis in breast cancer. Nat Cell Biol 2009; 11: 1297-1304.

10. Iwanicki MP, Brugge JS. Transcriptional regulation of metastatic [Id] entity by KLF17. Genome Biol 2009; 10: 244

11. Dong $\mathrm{P}$, Kaneuchi M, Xiong $\mathrm{Y}, \mathrm{Cao} \mathrm{L}$, Cai M, Liu X et al. Identification of KLF17 as a novel epithelial to mesenchymal transition inducer via direct activation of TWIST1 in endometrioid endometrial cancer. Carcinogenesis 2013; 35: 760-768.

12. Liu FY, Deng YL, Li Y, Zeng D, Zhou ZZ, Tian DA et al. Down-regulated KLF17 expression is associated with tumor invasion and poor prognosis in hepatocellular carcinoma. Med Oncol 2013; 30: 425

13. Sun Z, Han Q, Zhou N, Wang S, Lu S, Bai C et al. MicroRNA-9 enhances migration and invasion through KLF17 in hepatocellular carcinoma. Mol Oncol 2013; 7: 884-894.

14. Massagué J. TGF- $\beta$ in cancer. Cell 2008; 134: 215-230.

15. Derynck R, Zhang Y E. Smad-dependent and Smad-independent pathways in TGF- $\beta$ family signaling. Nature 2003; 425: 577-584.

16. Elliott RL, Blobe GC. Role of transforming growth factor $\beta$ in human cancer. J Clin Oncol 2005; 23: 2078-2093.

17. Shi Y, Massagué J. Mechanisms of TGF- $\beta$ signaling from cell membrane to the nucleus. Cell 2003; 113: 685-700.

18. Siegel PM, Massagué J. Cytostatic and apoptotic actions of TGF- $\beta$ in homeostasis and cancer. Nat Rev Cancer 2003; 3: 807-821.

19. Bierie B, Moses HL. Tumour microenvironment: $\operatorname{TGF} \beta$ : the molecular Jekyll and Hyde of cancer. Nat Rev Cancer 2006; 6: 506-520.

20. Heldin $\mathrm{CH}$, Landstrom M, Moustakas A. Mechanism of TGF- $\beta$ signaling to growth arrest, apoptosis, and epithelial-mesenchymal transition. Curr Opin Cell Biol 2009; 21: 166-176.

21. Levy L, Hill CS. Alterations in components of the TGF- $\beta$ superfamily signaling pathways in human cancer. Cytokine and Growth Factor Rev 2006; 17: 41-58. 
22. Roberts $\mathrm{AB}$, Wakefield $\mathrm{LM}$. The two faces of transforming growth factor $\beta$ in carcinogenesis PNAS 2003; 100: 8621-8623.

23. Meulmeester E, Dijke PT. The dynamic roles of TGF- $\beta$ in cancer. J Pathol 2011; 223: 205-218.

24. Inman GJ. Switching TGF $\beta$ from a tumor suppressor to a tumor promoter. Curr Opin Genet Dev 2011; 21: 93-99.

25. Huang T, David L, Mendoza V, Yang Y, Villarreal M, De K et al. TGF- $\beta$ signalling is mediated by two autonomously functioning T $\beta$ RI: T $\beta$ RII pairs. EMBO J 2011; 30: 1263-1276.

26. Massagué J. A very private TGF- $\beta$ receptor embrace. Mol Cell 2008; 29: 149-150.

27. Massagué J, Seoane J, Wotton D. Smad transcription factors. Genes Dev 2005; 19: 2783-2810.

28. Heldin $\mathrm{CH}$, Moustakas A. Role of Smads in TGF $\beta$ signaling. Cell Tissue Res 2012; 347: 21-26.

29. Feng $\mathrm{XH}$, Derynck $\mathrm{R}$. Specificity and versatility in TGF- $\beta$ signaling through smads. Ann Rev Cell Dev Biol 2005; 21: 659-693.

30. Ali A, Wang Z, Fu J, Ji L, Liu J, Li L et al. Differential regulation of the REGgammaproteasome pathway by p53/TGF-beta signalling and mutant p53 in cancer cells. Nat Commun 2013; 4: 2667

31. Cordenonsi M, Dupont S, Maretto S, Insinga A, Imbriano C, Piccolo S et al. Links between tumor suppressors: $\mathrm{p} 53$ is required for TGF- $\beta$ gene responses by cooperating with Smads. Cell 2003; 113: 301-314.

32. Dupont S, Zacchigna L, Adorno M, Soligo S, Volpin D, Piccolo S et al. Convergence of p53 and TGF- $\beta$ signaling networks. Cancer Lett 2004; 213: 129-138.

33. Wei J, Li Z, Chen W, Ma C, Zhan F, Wu W et al. AEG-1 participates in TGF-beta1-induced EMT through p38 MAPK activation. Cell Biol Int 2013; 37: 1016-1021.

34. Stankic M, Pavlovic S, Chin Y, Brogi E, Padua D, Norton L et al. TGF- $\beta$ Id1 signaling opposes Twist1 and promotes metastatic colonization via a mesenchymal-to-epithelia transition. Cell Rep 2013; 5: 1228-1242.

35. Kang Y, Chen CR, Massagué J. A self-enabling TGF-beta response coupled to stress signaling: Smad engages stress response factor ATF3 for Id1 repression in epithelial cells. Mol Cell 2003; 11: 915-926.

36. Feng XH, Lin X, Derynck R. Smad2, Smad3 and Smad4 cooperate with Sp1 to induce p15 (Ink4B) transcription in response to TGF-beta. EMBO J 2000; 19: 5178-5193.

37. Hong HY, Jeon WK, Kim SJ, Kim BC. 14-3-3 $\sigma$ is a new target up-regulated by transforming growth factor- $\beta 1$ through a Smad3-dependent mechanism. Biochem Biophys Res Commun 2013; 432: 193-197.

38. Spender LC, Carter MJ, O'Brien DI, Clark LJ, Yu J, Michalak EM et al. Transforming growth factor- $\beta$ directly induces p53-up-regulated modulator of apoptosis (PUMA) during the rapid induction of apoptosis in myc-driven B-cell lymphomas. J Biol Chem 2013; 288: 5198-5209.
39. Li H, Xu D, Li J, Berndt MC, Liu JP. Transforming growth factor beta suppresses human telomerase reverse transcriptase (hTERT) by Smad3 interactions with c-Myc and the hTERT gene. J Biol Chem 2006; 281: 25588-25600.

40. Frederick JP, Liberati NT, Waddell DS, Shi Y, Wang XF. Transforming growth factor beta-mediated transcriptional repression of c-myc is dependent on direct binding of Smad3 to a novel repressive Smad binding element. Mol Cell Biol 2004; 24: 2546-2559.

41. Fink SP, Mikkola D, Willson JK, Markowitz S. TGF-beta-induced nuclear localization of Smad2 and Smad3 in Smad4 null cancer cell lines. Oncogene 2003; 22: 1317-1323.

42. Tascilar M, Skinner HG, Rosty C, Sohn T, Wilentz RE, Offerhaus GJ et al. The Smad4 protein and prognosiss of pancreatic ductal adnocarcinoma. Clin Cancer Res 2001; 7: 4115-4121.

43. Losi L, Bouzourene $\mathrm{H}$, Benhattar J. Loss of Smad4 expression predicts liver metastasis in human colorectal cancer. Oncol Rep 2007; 17: 1095-1099.

44. White RA, Neiman JM, Reddi A, Han G, Birlea S, Mitra D et al. Epithelial stem cell mutations that promote squamous cell carcinoma metastasis. J Clin Invest 2013; 123: 4390-4404.

45. Papageorgis P, Cheng K, Ozturk S, Gong Y, Lambert AW, Abdolmaleky HM et al. Smad4 inactivation promotes malignancy and drug resistance of colon cancer. Cancer Res 2011; 71: 998-1008.

46. Zhang B, Halder SK, Kashikar ND, Cho YJ, Datta A, Gorden DL et al. Antimetastatic role of Smad4 signaling in colorectal cancer. Gastroenterology 2010; 138: 969-980.

47. Peinado $H$, Quintanilla M, Cano A. Transforming growth factor beta-1 induces snail transcription factor in epithelial cell lines: mechanisms for epithelial mesenchymal transitions. J Biol Chem 2003; 278: 21113-21123.

48. Miettinen PJ, Ebner R, Lopez AR, Derynck R. TGF-beta induced transdifferentiation of mammary epithelial cells to mesenchymal cells: involvement of type I receptors. J Cell Bio 1994; 127: 2.

(i) Cell Death and Disease is an open-access journal published by Nature Publishing Group. This work is licensed under a Creative Commons Attribution 4.0 International License. The images or other third party material in this article are included in the article's Creative Commons license, unless indicated otherwise in the credit line; if the material is not included under the Creative Commons license, users will need to obtain permission from the license holder to reproduce the material. To view a copy of this license, visit http://creativecommons.org/licenses/by/4.0/

Supplementary Information accompanies this paper on Cell Death and Disease website (http://www.nature.com/cddis) 